\title{
A Review of the Polymer for Cryogenic Application: Methods, Mechanisms and Perspectives
}

\author{
Duo Chen ${ }^{1}$, Juanzi Li ${ }^{1}$, Yuhuan Yuan ${ }^{1}$, Chang Gao ${ }^{1}$, Yunguang Cui ${ }^{2}$, Shichao $\mathrm{Li}^{2}{ }^{2}{ }^{*}, \mathrm{Xin} \mathrm{Liu}^{2}$, Hongyu Wang ${ }^{2}$, \\ Cong Peng ${ }^{2}$ and Zhanjun $\mathrm{Wu}^{2, *}$ \\ 1 Faculty of Mechanical Engineering Materials and Energy, School of Materials Science and Engineering, \\ Dalian University of Technology, Dalian 116024, China; chenduo93@163.com (D.C.); \\ jzl.1101.xpu@gmail.com (J.L.); yuanyuhuan0000@163.com (Y.Y.); rainy.gao723@dlut.edu.cn (C.G.) \\ 2 State Key Laboratory of Structural Analysis for Industrial Equipment, Faculty of Vehicle Engineering and \\ Mechanics, School of Aeronautics and Astronautics, Dalian University of Technology, Dalian 116024, China; \\ cyg1363956827@163.com (Y.C.); liuxindlut@dlut.edu.cn (X.L.); why2216@mail.dlut.edu.cn (H.W.); \\ dalianpcpc@126.com (C.P.) \\ * Correspondence: lsc1212@dlut.edu.cn (S.L.); wuzhj@dlut.edu.cn (Z.W.)
}

Citation: Chen, D.; Li, J.; Yuan, Y.; Gao, C.; Cui, Y.; Li, S.; Liu, X.; Wang, H.; Peng, C.; Wu, Z. A Review of the Polymer for Cryogenic Application: Methods, Mechanisms and Perspectives. Polymers 2021, 13, 320. https://doi.org/10.3390/polym1303 0320

Received: 28 December 2020

Accepted: 18 January 2021

Published: 20 January 2021

Publisher's Note: MDPI stays neutra with regard to jurisdictional claims in published maps and institutional affiliations.

Copyright: (C) 2021 by the authors Licensee MDPI, Basel, Switzerland. This article is an open access article distributed under the terms and conditions of the Creative Commons Attribution (CC BY) license (https:// creativecommons.org/licenses/by/ $4.0 /)$.

\begin{abstract}
Recently, the application of polymer-based composites at cryogenic conditions has become a hot topic, especially in aerospace fields. At cryogenic temperature, the polymer becomes more brittle, and the adverse effect of thermal stress induced by temperature is more remarkable. In this paper, the research development of thermoset and thermoplastic polymers for cryogenic applications are all reviewed. This review considers the literature concerning: (a) the cryogenic performance of modified thermoset polymers and the improving mechanisms of the reported modification methods; (b) the cryogenic application potential of some commercial thermoplastic polymers and the cryogenic performance of modified thermoplastic polymers; (c) the recent advance in the use of polymer for special cryogenic environment-liquid oxygen. This paper provides a comprehensive overview of the research development of the polymer for cryogenic application. Moreover, future research directions have been proposed to facilitate its practical applications in aerospace.
\end{abstract}

Keywords: polymer; modification; cryogenic properties; liquid oxygen compatibility

\section{Introduction}

Cryogenic liquids, such as liquid helium (LHe, $4 \mathrm{~K}$, liquid hydrogen $\left(\mathrm{LH}_{2}, 20 \mathrm{~K}\right)$, Liquid nitrogen $\left(\mathrm{LN}_{2}, 77 \mathrm{~K}\right.$ ), liquid oxygen (LOX,90 K), Liquid methane (LMG,112 K) play an important role in aerospace, superconductivity, energy and medical fields [1-3]. Due to the light weight, high specific strength, excellent corrosion resistance, good antifatigue performance and designability of the polymer-based composites, the research and application of polymeric matrix composites in the cryogenic fields has become a hot topic, especially in aerospace [4-10]. Polymer-based composites materials offer significant advantages in space applications with weight reduction of $25 \%$ to $35 \%$ and cost savings of near $50 \%[4,5,7]$. The current cost to send $1 \mathrm{Kg}$ of payload into geosynchronous transfer orbit using the SpaceX Falcon launcher is approximately $\$ 7500$ [8]. Thus, paying more attention to polymer matrix composites for cryogenic application is an interesting and meaningful work.

In cryogenic regions, the cryogenic tanks of launch vehicles are a particularly difficult application for polymer-based composite materials [6,9]. Not only must laminates used in these applications be very structurally efficient, but they must also contain extremely volatile cryogenic propellants (such as $\mathrm{LH}_{2}$ and LOX) [9]. A brief introduction of composites cryogenic tank research process in some projects is shown below. In 1987, McDonnell Douglas Corporation (MDC) completed the first $\mathrm{LH}_{2}$ composite cryogenic tank for a single stage to orbit (SSTO) spaceplane (X-30). This tank was fabricated using the thermoplastic 
graphite-reinforced material with a high glass transition temperature [5,7]. In 1994, the $\mathrm{LH}_{2}$ composite cryogenic tank of DC-XA was fabricated in two halves using a carbon/epoxy material by Douglas Aircraft Company [8]. At the same time, Lockheed Martin Space Systems Company build a honeycomb (HC) sandwich structure composites $\mathrm{LH}_{2}$ tank of the reusable launch vehicle (RLV) X-33 with the carbon/epoxy prepreg. Subsequently, other reusable launch vehicles such as orbital test vehicle (OTV) X-34 continued to evaluate composite cryogenic tank [11]. In the 2010s, during the composite cryogenic tank technology development (CCTD) project of NASA's Game Changing Development Program (GCDP), polymeric matrix composite cryogenic tanks with diameters of $2.4 \mathrm{~m}, 5.5 \mathrm{~m}$ and $10 \mathrm{~m}$ were built by the Boeing Company [5]. In 2014, during the Cryogenic Hypersonic Advanced Tank Technologies (CHATT) of the European Commission's Seventh Framework Program, a polymeric matrix composites cryogenic tank with a Polyethylene liner was manufactured [6]. In 2016, a $12 \mathrm{~m}$ diameter polymeric matrix composites LOX tank was fabricated by Space Exploration Technologies Corporation (Space X) [12]. This composites LOX tank was the largest cryogenic tank ever produced so far.

Although most of the above projects attempt to adopt mature material systems to reduce technical risks, there are still various problems for lack of enough information about the performance of polymeric composites under cryogenic environment [3-8]. Numerous works on the design and analysis of composite cryogenic tank has intensified since the failure of the X-33 RLV fuel tank, where fuel leakage occurred on the tank wall. The leakage was due to the fractures in the polymer and the high thermal stress caused by the mismatch of coefficient of thermal expansion (CTE) between the polymer and carbon fiber [12-18]. While, for reusable launch vehicles, the cryogenic performance of polymer-based composites under thermal and mechanical cyclic load is one of the most critical issue. Shindo's research group has studied the Delamination growth mechanisms and fatigue behavior of fiber reinforced polymer based woven composites under Mode I [19], Mode II [20], Mode III [21] and mixed-mode I/II [22] fatigue loadings at $77 \mathrm{~K}$ and $4 \mathrm{~K}$. The fatigue delamination growth rates of fiber reinforced polymer-based woven composites at $77 \mathrm{~K}$ and $4 \mathrm{~K}$ were lower than those at room temperature. Their interesting and meaningful work can lay a foundation for the design and application of polymer-based composites in cryogenic environment. At cryogenic temperature, when the fiber-reinforced polymer-based composites structure is subjected to combined thermal and mechanical loads, microcracks may initiate at loads well below the ultimate strength of the composite materials [23]. The maximum residual thermal stress in the carbon/epoxy composite is the longitudinal tensile stress in the matrix, which is a potential danger to the safety of composites structure for cryogenic use [24]. Meanwhile, the residual thermal stress has a significant effect on the stress distributions near the crack fronts in the composites at cryogenic temperatures [25].

Therefore, improving the mechanical properties including strength, ductility, impact strength and reducing the CTE of the polymer is desirable in developing high-performance composites for cryogenic engineering applications.

The polymers used in composite applications include thermosets and thermoplastics, or blends of the two. In thermoset composites, the matrix starts as low molecular weight material. During the curing process, the resin forms a rigid, high molecular weight structure. This rigidity is caused by the crosslinks (usually covalent bonds) formed among the polymer chains, which give the resin strength and thermal stability. As the crosslinking density (crosslinks per unit volume) increases and chain length decreases, the movement of polymer chains is more constrained and the resin becomes stiffer. This effect is magnified when the resin is exposed to cryogenic temperatures [11,14]. As Figure 1a shows, taking tensile properties as an example, the tensile strength, modulus and fracture strain of thermoset polymers demonstrate a dramatic change. Many works have been done to enhance the toughness and strength of thermoset polymers at room temperature. Very often, these properties can be effectively improved by introducing various toughening agents, such as inorganic fillers, block copolymer, hyperbranched polymer, reactive diluents, reactive liquid rubber, and thermoplastic $[17,18,26-32]$. Such research has made remarkable achieve- 
ments. Thus, it is feasible to improve the mechanical properties of the thermoset polymer at cryogenic temperature by adopting similar methods. Unlike thermoset polymers, the thermoplastic polymer does not crosslink among polymer backbone chains, which gives thermoplastic composites the unique ability to be reprocessed by melting and reconsolidating [33]. In contrast to thermoset polymer, the thermoplastic polymer's mechanical properties under different environments exhibit a similar variation trend (Figure 1b). To date, due to the limitation of relatively complicated manufacturing process and high cost, no large-scale studies have been performed to investigate the mechanical performance of thermoplastic polymer and its composites under cryogenic temperature [34]. With the development of science and technology, thermoplastic polymers will have a better prospect application in the cryogenic engineering field based on the high toughness, recycle ability.
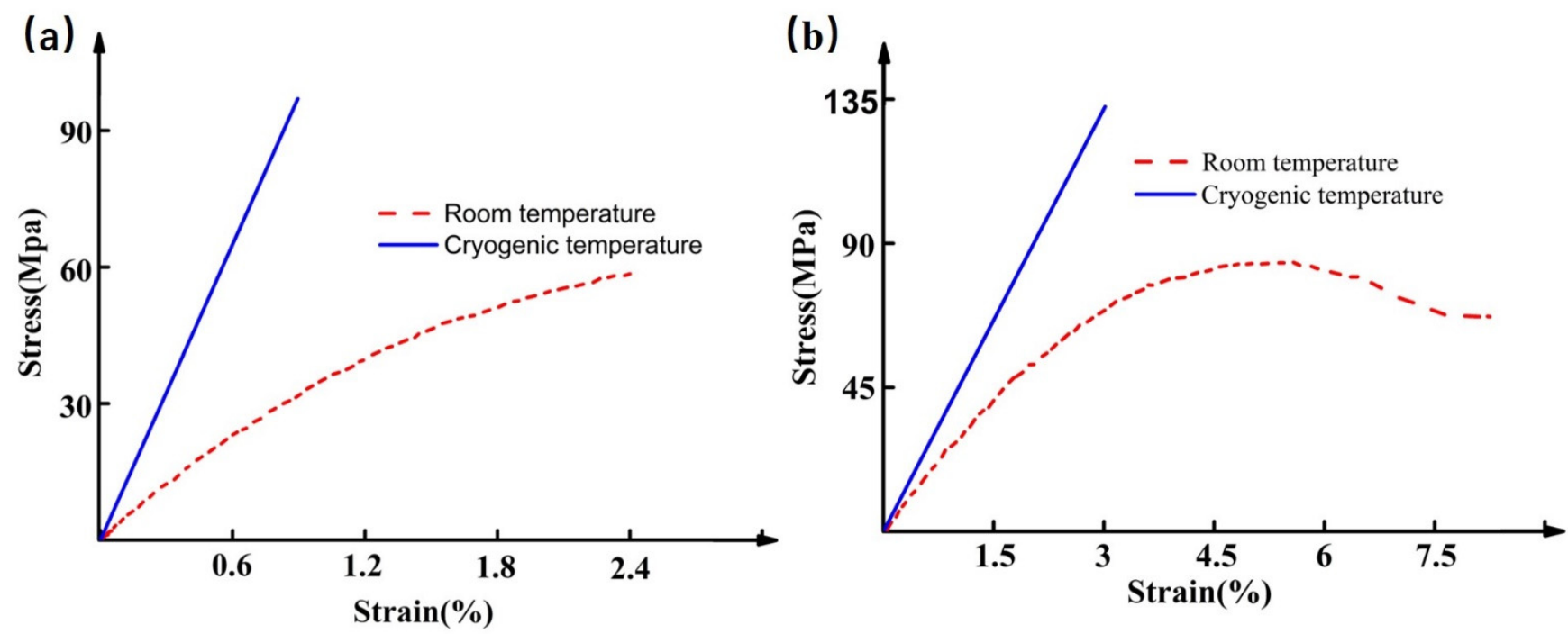

Figure 1. The typical tensile stress-strain behaviors of (a) thermoset polymer and (b) thermoplastic polymer under room and cryogenic temperature.

Figure 2 provides an overview of the research and development of polymer and modified polymer for cryogenic application. The modification approaches, effects and mechanisms of the modified polymer at cryogenic temperature are all summarized. In this review, as mentioned above, Sections 2 and 3 present the research and development of thermoset and thermoplastic polymer under cryogenic applications. To the polymer-based composites applied for LOX, besides meeting the physical requirements at cryogenic temperature, the polymer-based composites adopted in LOX systems must also be chemically compatible with LOX. Subsequently, Section 4 presents the recent advances in the use of polymer for liquid oxygen. Finally, Section 5 summarizes the advances made on polymers for cryogenic applications, where we are now, and provides insight into future research in the cryogenic polymer-based composites. 


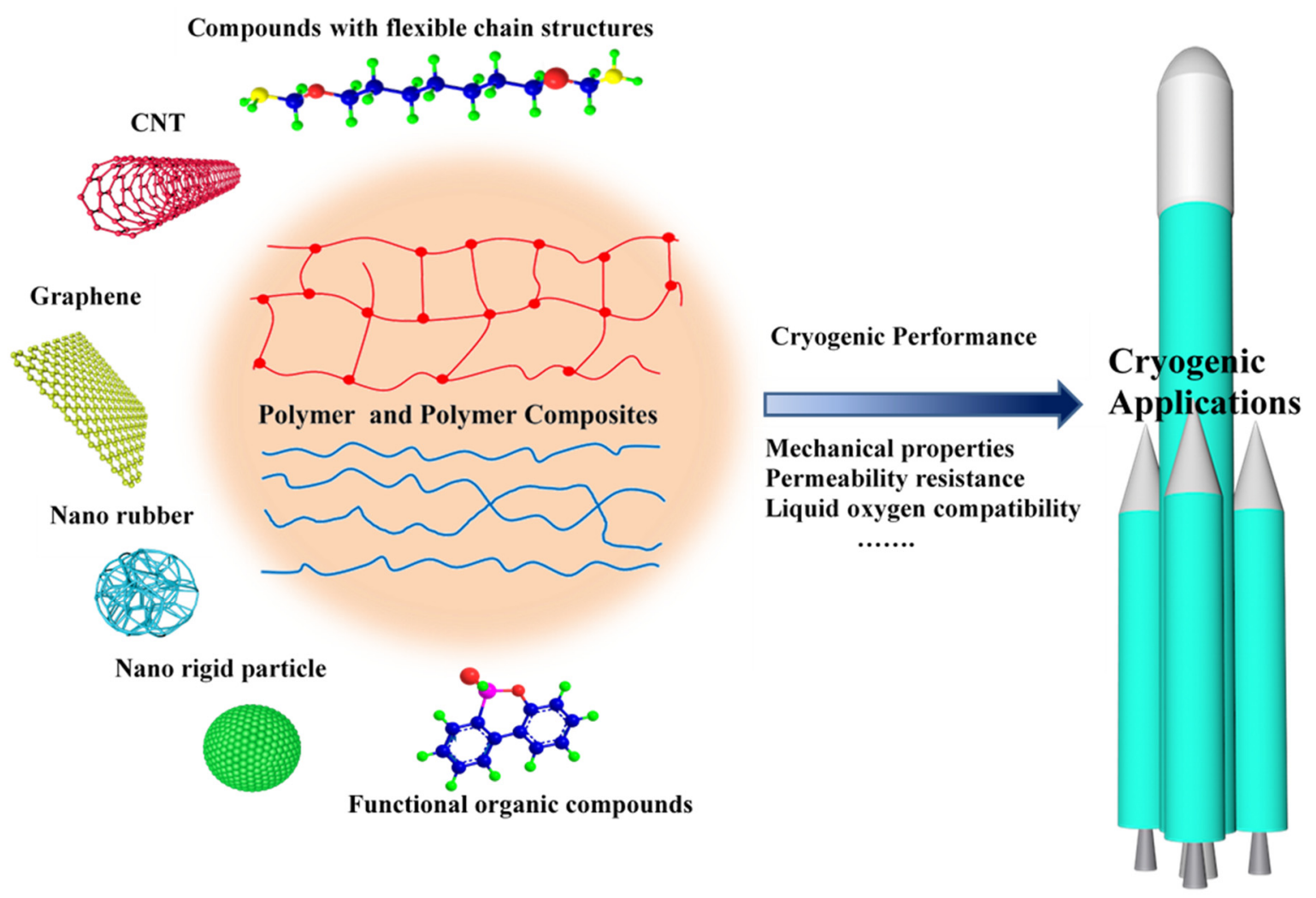

Figure 2. Schematic illustration of the main contents in this review, including the cryogenic performance of thermoset, thermoplastic polymer and the modified polymer by introducing various modifiers, such as graphene, carbon nanotubes, nanoparticle, rubber, compounds with flexible chain structures and functional organic compounds.

\section{The Research Development of Thermoset Polymer for Cryogenic Application}

Generally, thermoset polymers such as epoxy (EP) resin, phenolic resin, polyester resin, bismaleimide resin, etc., are made of an initial liquid mixture of polyfunctional organic molecules. They gradually react with each other to form a three-dimensional cross-link network [35]. Among these numerous thermoset polymers, EP-based thermosets hold a prominent position for their high adhesion strength, excellent mechanical properties and good processability $[27,36]$. However, the high cross-link density lowers the fracture toughness and the resistance to crack initiation of the thermosets. This largely restricts their applications in a cryogenic environment [11]. Therefore, toughening of thermoset polymers has become a necessity to ensure the feasibility of these materials for practical applications. These drawbacks can be overcome by decreasing the cross-link density of thermoset resin or incorporating heterogeneous phases with some additives such as rigid inorganic nanomaterial, soft polymers (elastomer, block copolymers, high-performance plastic polymer and hyperbranched polymer) [18,26-32].

In this section, the research and application development under the cryogenic temperatures of thermoset polymers modified by various components (rigid nanomaterial, thermoplastic, rubber and other compounds) are summarized. Meanwhile, the effects on the cryogenic properties of thermoset polymers modified by changing their cross-link structure are also reviewed.

Table 1 exhibits previous works on the mechanical properties of thermoset polymers modified by nanomaterial, thermoplastic, rubber and other compounds at the cryogenic temperatures. From this table, the current mechanical level that the modified thermoset polymer can achieve at cryogenic temperature could be clearly realized. As shown in Figure 3, we also summarized the modification effect of different method on tensile properties at different temperatures. Compared with pristine polymers, the increase or decrease in tensile properties of modified polymers at room temperature doesn't mean that would 
demonstrate the same variation trend at cryogenic temperatures. Introducing the fillers into polymers, such as CNTs, Graphene and PES, the tensile strength and modulus of polymers at room or cryogenic temperature all could be improved. However, the effects of modification method cannot be predicted. Meanwhile, the research progress about such methods is described in detail below.

Table 1. Cryogenic mechanical properties of modified thermoset polymers.

\begin{tabular}{|c|c|c|c|c|c|}
\hline Resin System ${ }^{1}$ & Modifier $^{1}$ & Content & Temperature & Mechanical Properties & Ref. \\
\hline DGEBF/DETDA & MWCNTS & $0.5 w \mathrm{t} \%$ & $77 \mathrm{~K}$ & $\begin{array}{l}\text { Tensile strength: } 119.35 \mathrm{MPa} \\
\text { Tensile modulus: } 5.26 \mathrm{GPa} \\
\text { Tensile fracture strain: } 3.20 \% \\
\text { Impact strength: } 35.56 \mathrm{KJ} / \mathrm{m}^{2}\end{array}$ & [37] \\
\hline $\begin{array}{l}\text { DGEBA/EP- } \\
\text { PU/DETDA }\end{array}$ & MWCNTS-NH ${ }_{2}$ & $0.2 \mathrm{wt} \%$ & $77 \mathrm{~K}$ & $\begin{array}{c}\text { Tensile strength: } 120 \mathrm{MPa} \\
\text { Tensile modulus: } 7.0 \mathrm{GPa} \\
\text { Flexural strength: } 275 \mathrm{MPa} \\
\text { Flexural modulus: } 8.0 \mathrm{GPa} \\
\text { Impact strength: } 32 \mathrm{KJ} / \mathrm{m}^{2} \\
\text { Fracture toughness: } 3.25 \mathrm{MPa} \cdot \mathrm{m}^{1 / 2}\end{array}$ & [38] \\
\hline $\begin{array}{l}\text { DGEBA/15 wt\% } \\
\text { Oligomer/D-230 }\end{array}$ & $\mathrm{O}-\mathrm{CNTs}$ & $0.5 w t \%$ & $77 \mathrm{~K}$ & $\begin{array}{l}\text { Tensile strength: } 91.7 \mathrm{MPa} \\
\text { Tensile modulus: } 3.6 \mathrm{GPa} \\
\text { Impact strength: } 46 \mathrm{KJ} / \mathrm{m}^{2}\end{array}$ & [39] \\
\hline DEGBA/DETDA & Graphene & $0.1 \mathrm{wt} \%$ & $77 \mathrm{~K}$ & $\begin{array}{l}\text { Tensile strength: } 140.0 \mathrm{MPa} \\
\text { Tensile modulus: } 7.0 \mathrm{GPa} \\
\text { Impact strength: } 21.9 \mathrm{KJ} / \mathrm{m}^{2}\end{array}$ & [40] \\
\hline DGEBA/DETA & GO-PDA & $1 \mathrm{wt} \%$ & $150 \mathrm{~K}$ & $\begin{array}{c}\text { Tensile strength: } 70 \mathrm{MPa} \\
\text { Tensile modulus: } 3.29 \mathrm{GPa} \\
\text { Tensile fracture strain: } 2.50 \% \\
\text { GIC }: 666.32 \mathrm{~J} / \mathrm{m}^{2} \\
\mathrm{~K}_{\mathrm{IC}}: 1.58 \mathrm{MN} / \mathrm{m} 3 / 2\end{array}$ & [41] \\
\hline DGEBA/diluent/D-230 & FGSs & $1.6 \mathrm{wt} \%$ & $143 \mathrm{~K}$ & $\begin{array}{l}\text { Tensile strength: } 82.91 \mathrm{MPa} \\
\text { Tensile modulus: } 5.54 \mathrm{GPa} \\
\text { Tensile fracture strain: } 1.65 \%\end{array}$ & [42] \\
\hline DGEBA/TETA & $\mathrm{GO}$ & $0.2 \mathrm{wt} \%$ & $193 \mathrm{~K}$ & $\begin{array}{c}\text { Tensile strength: } 150 \mathrm{MPa} \\
\text { Tensile modulus: } 4.7 \mathrm{GPa} \\
\text { Tensile fracture strain: } 3.7 \%\end{array}$ & [43] \\
\hline DGEBA/D-230 & $\mathrm{Fe}_{3} \mathrm{O}_{4} / \mathrm{GO}$ & $0.5 w \mathrm{t} \%$ & $77 \mathrm{~K}$ & $\begin{array}{c}\text { Tensile strength: } 96.4 \mathrm{MPa} \\
\text { Tensile modulus: } 5.9 \mathrm{GPa} \\
\text { Tensile fracture strain: } 19.5 \% \\
\text { Impact strength: } 44.2 \mathrm{MPa} \\
\text { KIC }_{\text {IC }} 2.1 \mathrm{MN} / \mathrm{m}^{3 / 2}\end{array}$ & [44] \\
\hline DGEBF/DETD & $\mathrm{SiO}_{2}$ & $4 w t \%$ & $77 \mathrm{~K}$ & $\begin{array}{l}\text { Tensile strength: } 77.63 \mathrm{MPa} \\
\text { Tensile modulus: } 4.62 \mathrm{GPa} \\
\text { Tensile fracture strain: } 2.2 \%\end{array}$ & [45] \\
\hline DGEBA/BCE/BCP & Nano-clay & $3 w t \%$ & $77 \mathrm{~K}$ & $\begin{array}{l}\text { Tensile strength: } 169 \mathrm{MPa} \\
\text { Tensile modulus: } 5.5 \mathrm{GPa} \\
\text { Tensile fracture strain: } 2.2 \%\end{array}$ & [46] \\
\hline DGEBA/DDM & KH560-modified silica & $1 \mathrm{wt} \%$ & $90 \mathrm{~K}$ & $\begin{array}{c}\text { Tensile strength: } 169 \mathrm{MPa} \\
\text { Tensile modulus: } 9.0 \mathrm{GPa} \\
\text { Tensile fracture strain: } 2.5 \%\end{array}$ & [47] \\
\hline DGEBF/DETD & PES & $20 \mathrm{phr}$ & $77 \mathrm{~K}$ & $\begin{array}{l}\text { Tensile strength: } 86.64 \mathrm{MPa} \\
\text { Tensile modulus: } 4.32 \mathrm{GPa} \\
\text { Tensile fracture strain: } 2.87 \%\end{array}$ & [48] \\
\hline
\end{tabular}


Table 1. Cont.

\begin{tabular}{|c|c|c|c|c|c|}
\hline Resin System ${ }^{1}$ & Modifier $^{1}$ & Content & Temperature & Mechanical Properties & Ref. \\
\hline DGEBA/D-230 & $\mathrm{PBT} / \mathrm{PEI} / \mathrm{PC}$ & $1.5 \mathrm{wt} \%$ & $77 \mathrm{~K}$ & $\begin{array}{l}\text { Impact strength: } 34.5 \mathrm{KJ} / \mathrm{m}^{2}(\mathrm{PBT}) \\
\text { Impact strength: } 39.8 \mathrm{KJ} / \mathrm{m}^{2}(\mathrm{PEI}) \\
\text { Impact strength: } 36.01 \mathrm{KJ} / \mathrm{m}^{2}(\mathrm{PC})\end{array}$ & [49] \\
\hline DGEBA/DETDA & HTPU & $5 \mathrm{phr}$ & $77 \mathrm{~K}$ & $\begin{array}{l}\text { Tensile strength: } 161.67 \mathrm{MPa} \\
\text { Tensile modulus: } 6.89 \mathrm{GPa} \\
\text { Tensile fracture strain: } 2.58 \% \\
\text { Impact strength: } 30 \mathrm{KJ} / \mathrm{m}^{2}\end{array}$ & [50] \\
\hline DGEBF/DDM & EPSE & $5 \mathrm{wt} \%$ & $90 \mathrm{~K}$ & $\begin{array}{l}\text { Tensile strength: } 210 \mathrm{MPa} \\
\text { Tensile fracture strain: } 3 \%\end{array}$ & [51] \\
\hline DGEBF/DDM & EPSE & $5-8 w t \%$ & $77 \mathrm{~K}$ & $\begin{array}{c}\mathrm{K}_{\mathrm{IC}}: 2.35 \mathrm{MN} / \mathrm{m} 3 / 2(5 \mathrm{wt} \%) \\
\mathrm{K}_{\mathrm{IC}}: 2.6 \mathrm{MN} / \mathrm{m} 3 / 2(8 \mathrm{wt} \%)\end{array}$ & [52] \\
\hline DGEBF/DETD & NR & $15 \mathrm{phr}$ & $77 \mathrm{~K}$ & $\begin{array}{c}\text { Tensile strength: } 129.98 \mathrm{MPa} \\
\text { Tensile modulus: } 4.13 \mathrm{GPa} \\
\text { Tensile fracture strain: } 3.15 \% \\
\mathrm{~K}_{\mathrm{IC}}: 2.2 \mathrm{MN} / \mathrm{m}^{3 / 2}\end{array}$ & [53] \\
\hline DGEBA/NA/A-178 & HК021 & $80 \mathrm{phr}$ & $77 \mathrm{~K}$ & LSS: 9.7Mpa & [54] \\
\hline DGEBF/MeTHPA & H30 & $10 w t \%$ & $77 \mathrm{~K}$ & $\begin{array}{l}\text { Tensile strength: } 115.6 \mathrm{MPa} \\
\text { Tensile modulus: } 3.8 \mathrm{GPa} \\
\text { Tensile fracture strain: } 3.1 \% \\
\text { Impact strength: } 32 \mathrm{KJ} / \mathrm{m}^{2}\end{array}$ & [55] \\
\hline
\end{tabular}

1 Abbreviations: DGEBF, diglycidyl ether of bisphenol-F; DETD, diethyl toluene diamine; MWCNTs, Multi walled carbon nanotubes; DGEBA, diglycidyl ether of bisphenol-A;EP-PU, epoxy grafted polyurethane; MWCNTS-NH2, aminated Multi walled carbon nanotubes; D-230, polyoxypropylenediamine; O-CNTs, oxidized multi-walled carbon nanotubes; GO-PDA, graphene oxide/poly pphenylenediamine;FGs, functionalized graphene sheets.TETA, Triethylene tetra amine;GO, graphene oxide; BCE, 2,2-bis(4-cyanatophenyl) isopropylidene; $\mathrm{BCP}$, block copolymer; DDM, 4,4'-diaminodiphenylmethane; KH-560, 3-glycidoxypropyltrimethoxysilane; PES, Polyethersulfone; PBT, Polybutylene terephthalate; PEI, Polyether imide; PC, Polycarbonate; HTPU, hydroxyl-terminated polyurethanes; EPSE, epoxy-functionalized polysiloxane;NR, carboxylic nitrile-butadiene nano-rubber; NA, nadictetrahydric-methylanhydride; A-178, commercial name of silane coupling agent; HK021, commercial name of diol molecule; MeTHPA, Methyltetrahydrophthalic anhydride; H30, commercial name of hyperbranched polyester.

(a)

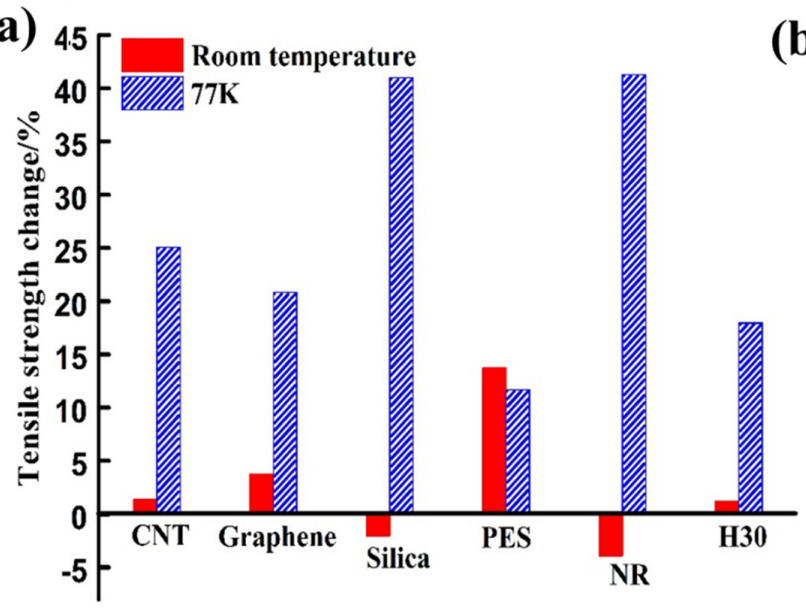

(b)

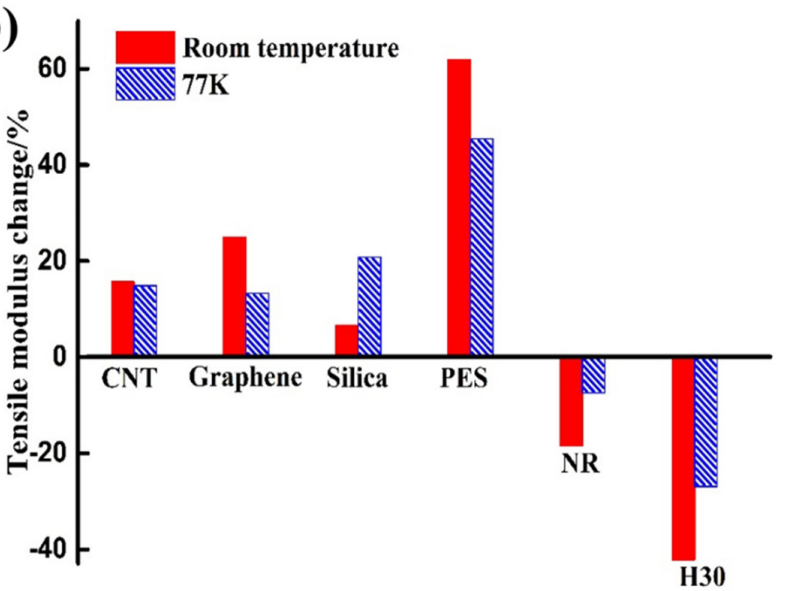

Figure 3. (a) The tensile strength and (b) tensile modulus change of CNT [37], graphene [40], silica [45], PES [48], NR [52] and H30 [55] modified polymer composites compared with unmodified polymers at room and cryogenic temperature.

\subsection{Enhancing the Cryogenic Performance of Thermoset Polymer by Introducing the Rigid} Nanomaterial

\subsubsection{Carbon Nanotubes}

Carbon nanotubes (CNTs) have attracted a huge deal of attention owing to their exceptional mechanical and physical properties. High aspect ratio (length/diameter) 
and low density have made them a promising reinforcing material for polymer matrix composites [55-57]. There are some ways to enhance polymer matrix composites with carbon nanotubes (CNTs). Such as mixing CNTs into a polymer matrix, grafting CNTs on the fiber for the matrix-fiber interface region, and inserting paper-formed CNTs to the laminar interface $[30,55]$. Among these methods, mixing CNTs into the polymer matrix is the most efficient, economical and convenient one. However, weak interfacial bonding between CNTs and polymers leads to poor stress transfer, limiting the full realization of CNTs as reinforcements for polymers [33,57-59].

Chen et al. studied the cryogenic mechanical properties of MWCNTs reinforced EP nanocomposites [37]. The MWCNTs were treated using a mixture of concentrated sulfuric and nitric acids. The acid-treated MWCNTs were dispersed into the epoxy via the ultrasonic technique. The tensile mechanical properties of epoxy nanocomposites containing MWCNTs with weight fractions of $0.02 \%, 0.05 \%, 0.2 \%, 0.5 \%, 1 \%$, and $2 \%$ were tested at room temperature and $77 \mathrm{~K}$ (Figure $4 \mathrm{a}, \mathrm{b}$ ). It was found that the tensile strength, toughness and impact strength reached the maximum at cryogenic temperature when the MWCNT content was $0.5 \mathrm{wt} \%$. With the temperature decreasing from room temperature to cryogenic temperature, the big differences of thermal expansion coefficients between EP and the uniformly dispersed MWCNTs led to a thermal contraction of the EP matrix. The contraction generated a stronger MWCNT-EP interfacial bonding. Due to the strong interfacial bonding, the interface is capable of transferring load more effectively from the polymer to the MWCNTs. Thus, the cryogenic mechanical properties of polymers were enhanced by MWCNTs.

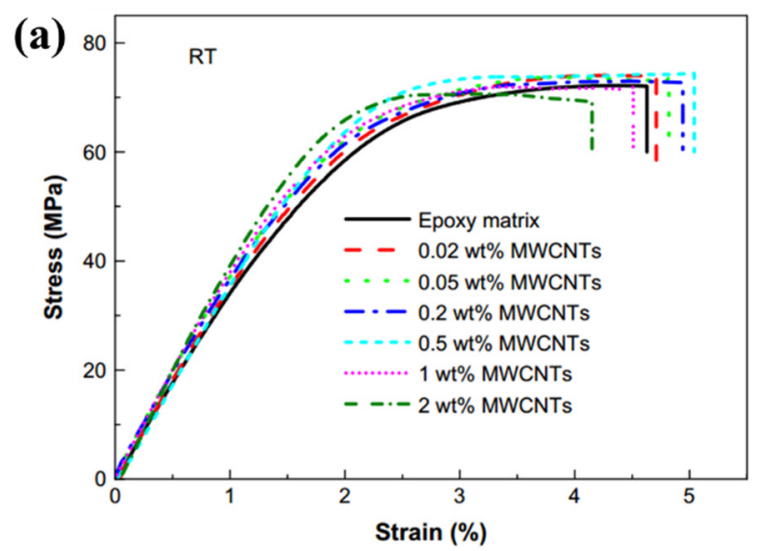

(c)

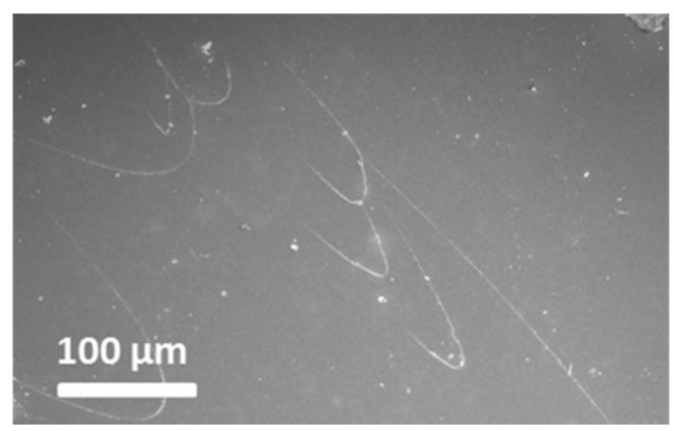

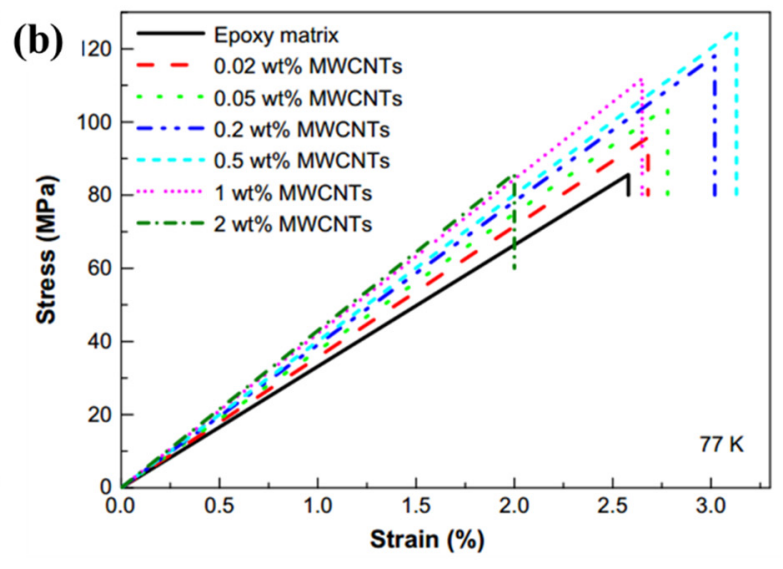

(d)

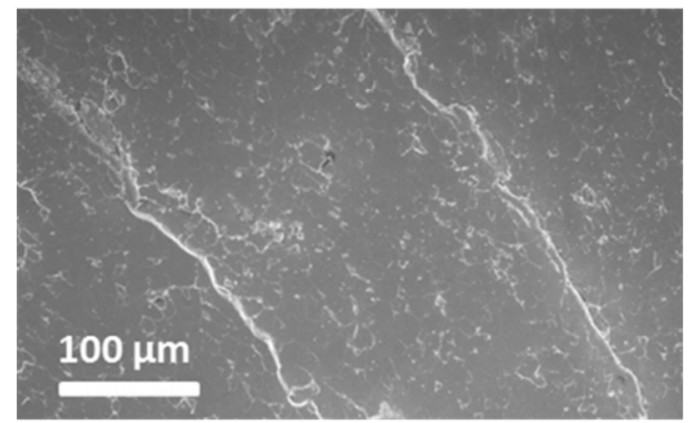

Figure 4. The stress-strain curves of MWCNT/epoxy nanocomposites (a) at room temperature and (b) at $77 \mathrm{~K}$. Reused with permission from Ref. [37]. Copyright 2009 Elsevier. The SEM images of impact fracture surfaces at $77 \mathrm{~K}$ of (c) epoxy and (d) 0.5 wt CNTs modified epoxy. Reused with permission from Ref. [39]. Copyright 2013 Elsevier.

The strengthening effects of aminated MWCNTs $\left(\mathrm{MWCNTs}-\mathrm{NH}_{2}\right)$ on the cryogenic mechanical performance of EP-based composites were discussed by Jia, et al. [38]. The EP-based composites contain a 30\% soft polymer modifier, EP grafted polyurethane (PU), which was synthesized by controlling the reaction between -OH in EP and -NCO in PU. The 
cryogenic $(77 \mathrm{~K})$ mechanical properties of MWCNTs- $\mathrm{NH}_{2}$ modified EP-based composites increased up to $0.2 \mathrm{wt} \%$ MWCNTs- $\mathrm{NH}_{2}$ and then decreased with higher MWCNTs- $\mathrm{NH}_{2}$ content. For $0.2 \mathrm{wt} \%$ MWCNTs- $\mathrm{NH}_{2}$ modified EP-based composites, the tensile strength, flexural strength, impact strength and fracture toughness at $77 \mathrm{~K}$ were enhanced by $31.2 \%$, $70.2 \%, 100.0 \%$ and $26.0 \%$, respectively, compared with those of neat EP. The existence of reactive groups $\left(-\mathrm{NH}_{2}\right)$ in MWCNTs- $\mathrm{NH}_{2}$, the best dispersibility of MWCNTs- $\mathrm{NH}_{2}(0.2 \%)$ in the EP matrix and the thermal contraction of the EP matrix can help in strengthening the interfacial interaction between MWCNTs- $\mathrm{NH}_{2}$ and EP matrix at cryogenic condition, resulting in an effective load transfer. As shown in Figure 4c,d, at cryogenic temperature, the fracture surface of CNTs modified epoxy is much rougher than epoxy and exhibits micromesh cracks. The addition of CNTs increased the resistance to crack propagation in epoxy. Hence, the toughness of the thermoset polymer is improved.

Similarly, the oxidized multi-walled carbon nanotubes (O-CNTs) were added to the epoxy using a reactive oligomer to enhance the cryogenic $(77 \mathrm{~K})$ mechanical properties of EP-based composites by Yi et al. [39]. In this research, the EP modified with $15 \mathrm{wt} \%$ oligomers containing $0.5 \mathrm{wt} \%$ of O-CNTs showed $69.5 \%$ improvements in impact strength at $77 \mathrm{~K}$, compared to the unmodified EP. Kim et al. found that the crack resistance and the fracture toughness of carbon fiber reinforced epoxy-based composites at cryogenic temperature $(123 \mathrm{~K})$ could also be enhanced by adding the aminated carbon nanotubes into the resin matrix [60]. The aminated CNTs were conducted by chemical surface treatment with triethylenetetramine (TETA). Except for aminated CNTs, the carboxyl (COOH) functionalized CNTs could also improve composites' mechanical properties. Prusty, et al. reported that the flexural strength of carboxyl $(\mathrm{COOH})$ functionalized CNTs modified EP-based composites increased by $16.2 \%$ at $198 \mathrm{~K}$, compared with pristine carbon nanotube reinforced epoxy-based composites [61]. Takeda et al. [62] found that the simultaneous addition of $0.5 \mathrm{wt} \%$ CNTs and $10 \mathrm{phr}$-butyl glycidyl ether (BGE) lead to the increase in the tension-tension fatigue lives for fiber reinforced bisphenol-F epoxy composites at $77 \mathrm{~K}$.The improvement in fatigue lives can be attributed to the fact that the fatigue life of composites is significantly affected by the matrix material because the introduction of CNTs and BGE resulted in the obviously enhanced glass fiber/epoxy interfacial adhesion [63].

\subsubsection{Graphene}

Graphene, a new two-dimensional carbon nanomaterial, known for its single-layered atom-thick flatbed structure, has brought a new dimension to the nanotechnology world due to its high thermal conductivity, electrical conductivity and mechanical stiffness $(130 \mathrm{GPa})[64,65]$. Graphene possesses a higher aspect ratio than CNTs, predominantly ideal for reinforcement. Compared with other nanofillers, the presence of graphene effectively prevented crack propagation by producing a large amount of plastic deformation [66-69], making it a promising candidate for enhancing the cryogenic properties of thermoset polymer. It has been reported that the uniform dispersion of nanofillers such as graphene and CNTs into polymers plays a significant role in determining the mechanical, thermal, and physical properties of the resultant nanocomposites and is one of the challenging works [68,70]. It is also well confirmed that graphene functionalization could improve the dispersion of graphene in the polymer [71,72].

Shen et al. demonstrated that the introduction of graphene oxide sheets at a proper content of $0.1 \mathrm{wt} \%$ into the EP matrix could simultaneously enhance the cryogenic $(77 \mathrm{~K})$ tensile strength, Young's modulus, and impact strength [40]. The tensile and impact strengths of graphene/EP composite reached the maximum with an improvement of $10.5 \%$ and $23.7 \%$ at $77 \mathrm{~K}$, respectively. At the relatively low content, the graphene with a good dispersion can resist the propagation of cracks in the polymer. Thus, the fracture surfaces of the graphene-modified EP are rougher than those of pure EP (Figure 5a,b). Hussein et al. synthesized a hybrid filler based on graphene oxide/poly p-phenylenediamine (GO-PDA) [41]. At $153 \mathrm{~K}$, the GO-PDA nanofiller could improve the strength, fracture strain, and toughness of EP when added at a low content. Lee et al. added functionalized 
graphene sheets (FGs) to the epoxy resin to enhance its cryogenic performance [35]. FGS/EP nanocomposites' strength and toughness increased by $200 \%$ and $700 \%$ at $143 \mathrm{~K}$, respectively, at the loading of $1.6 \mathrm{wt} \%$ FGS. And the CTE of polymer resin reduced about $25 \%$ at the same contents. $\mathrm{A} \mathrm{Fe}_{3} \mathrm{O}_{4}$ modified graphene oxide $\left(\mathrm{Fe}_{3} \mathrm{O}_{4} / \mathrm{GO}\right)$ nanofiller, which was synthesized by a modified co-precipitation reaction between $\mathrm{Fe}^{2+}$ and $\mathrm{Fe}^{3+}$ ions in the presence of GO, was used to modify the cryogenic mechanical properties of the polymer by $\mathrm{He}$ et al. [44]. The study reflected the CTE of $\mathrm{Fe}_{3} \mathrm{O}_{4} / \mathrm{GO}(0.5 \mathrm{wt} . \%)$ modified EP composite is decreased by $51.6 \%$ compared with neat EP. Besides, compared to CF/EP composite, the micro-cracks density of $\mathrm{Fe}_{3} \mathrm{O}_{4} / \mathrm{GO}$ modified CF/EP composite at $77 \mathrm{~K}$ is decreased by $60.0 \%$. Recently, Huang et al. compared two different approaches employing GO into $\mathrm{CF} / \mathrm{EP}$ composites. One is dispersing GO into EP matrix, the other is coating it onto the surface of CF [45]. The result demonstrated that two ways could improve the mechanical properties of composites at cryogenic temperature. However, the latter is a more desirable employment method in the fabrication of GO-modified polymer-based composites for the strong chemical interaction and mechanical interlocking between $\mathrm{CF}$ and polymer. At $77 \mathrm{~K}$, the bending strength and modulus of GO coating CF reinforced composites increased by $47.62 \%$ and $23.28 \%$, respectively, compared with the controlled sample. The above researches all confirmed that the toughening mechanisms of graphene are crack deflection and plastic void growth due to the improved interface strength caused by polymer/filler CTE mismatch (Figure 5c) at cryogenic temperature.

(a)

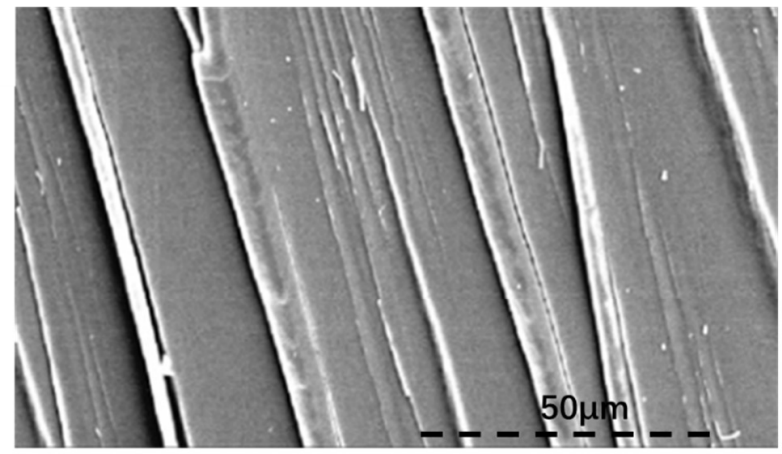

(c)

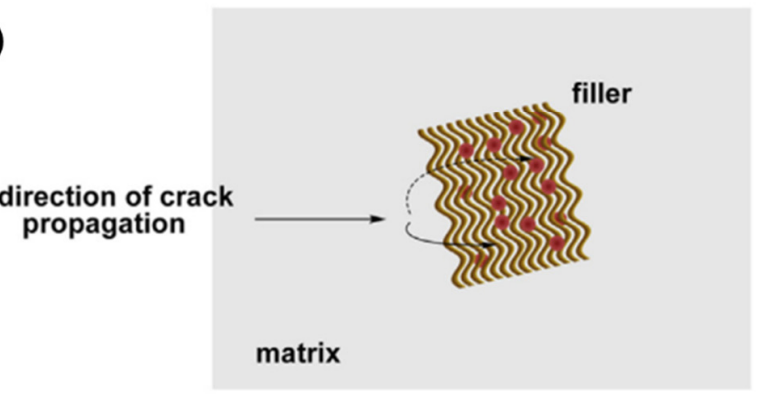

(b)
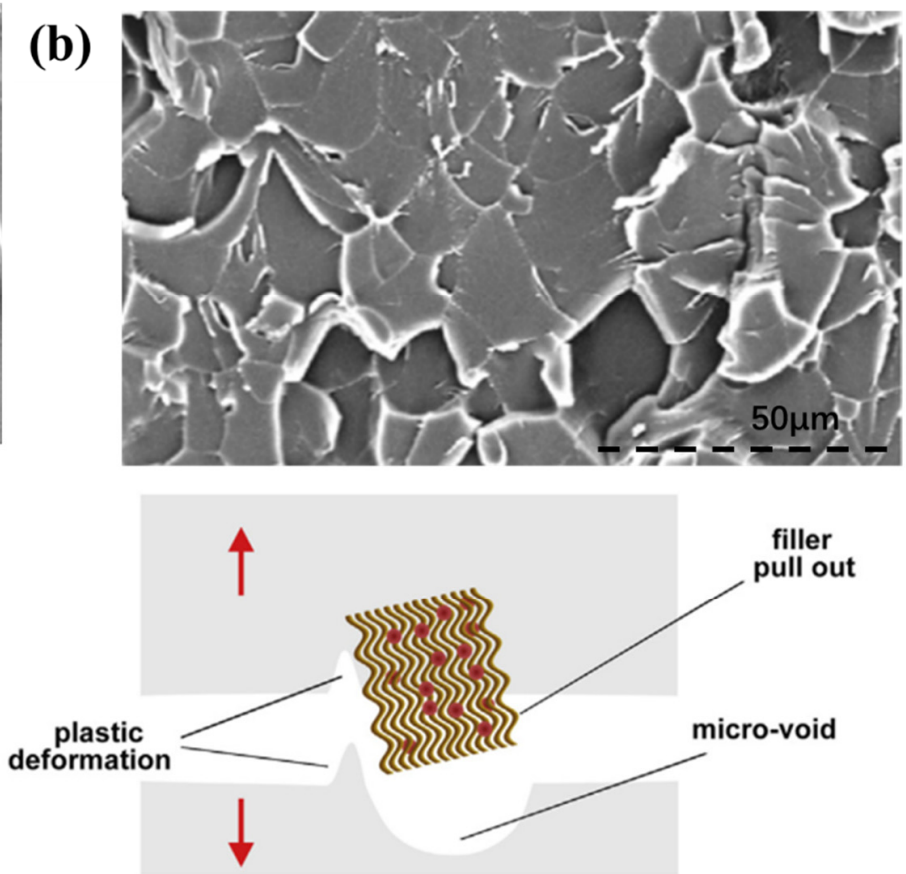

Figure 5. (a,b) SEM images of the impact fracture surface at $77 \mathrm{~K}$ of pure epoxy and graphene/epoxy composites containing $0.1 \mathrm{wt} \%$ graphene. Reused with permission from Ref. [40]. Copyright 2012 Elsevier. (c) Schematic of the fracture mechanism of graphene/epoxy composites. Reused with permission from Ref. [41]. Copyright 2017 Elsevier.

\subsubsection{Other Inorganic Nanomaterials}

Besides graphene and CNTs, there are other inorganic nanoparticles used to improve the mechanical properties of polymeric composites, such as silica and nanoclay $[26,27,73,74]$. Low cost, ease of fabrication and excellent compatibility with polymer have made them more readily available than many other kinds of nanofillers like CNTs and graphene [74-78].

Huang et al. found that the tensile strength, tensile fracture strain of $\mathrm{SiO}_{2} / \mathrm{EP}$ nanocomposites could be increased by almost $42 \%$ and $44 \%$ respectively by adding $4 \mathrm{wt} \% \mathrm{SiO}_{2}$ to the diglycidyl ether of bisphenol-F (DGEBF) type EP [45]. With the increase of silicate content, 
Young's modulus at $77 \mathrm{~K}$ of the $\mathrm{SiO}_{2} / \mathrm{EP}$ nanocomposite increased and the average CTE from $298 \mathrm{~K}$ to $77 \mathrm{~K}$ decreased (Figure $6 \mathrm{a}, \mathrm{b}$ ). The $\mathrm{SiO}_{2} / \mathrm{EP}$ nanocomposite was prepared by using DGEBF type EP and tetraethylorthosilicate via the sol-gel process. Besides, nanosilica can also be added to EP resin with the direct blending method. This method is more convenient, practical, and economical. By directly adding $\mathrm{SiO}_{2}$ nanoparticles into the epoxy matrix, the contact forces and energy absorption capacities of fiber-reinforced composites are improved during the low-velocity impact (LVI) test at a cryogenic temperature [79]. However, as the nano filler itself usually has a strong tendency to agglomerate, adding the filler into the EP directly will result in the non-uniform dispersion of nanofiller and reduce affinity between the filler and the matrix [71]. Wang studied the dispersion of silica modified by different silane coupling agents (SCAs) in DGEBA type EP resin and tested the mechanical properties of these different silica/EP nanocomposites at cryogenic temperature $(77 \mathrm{~K})$ [47]. Compared with other coupling agents, the KH560-modified silica enhanced EP nanocomposite has superior performance at cryogenic temperature.

Layered silicate, such as nanoclay, becomes a more promising nanofiller in EP-based nanocomposites due to the high intercalation chemistry, high aspect ratio, thermal stability and low cost. It has been shown in the Unmanned Space Vehicle (USV)-CRYOTANK project of the Italian Aerospace Research Program that the organo-modified nanoclays and layered hydroxides could improve the barrier properties of cyanate-esters and EP based polymer matrix composites [80]. The research conducted by NASA Glenn Research Center has demonstrated that adding a layered silicate clay to an appropriate matrix can significantly improve the performance of a polymer matrix composite for cryogenic tank applications [81]. The nanoclay enhanced EP nanocomposites with 70\% lower hydrogen permeability than the base EP resin. Due to a clamping force induced on nanoclay by negative thermal expansion, the lap joint shear strength of nanoclay $(1 \mathrm{wt} \%)$ modified EP adhesive increased by $8.6 \%$ at $77 \mathrm{~K}$ [82]. Nevertheless, researchers investigated the mode I fracture toughness $\left(\mathrm{K}_{\mathrm{IC}}\right)$ of EP at cryogenic temperature $(123 \mathrm{~K})$, which was determined by the 3-point bending method with the single edge notch bend specimens with a very sharp pre-crack (Figure $6 c, d$ ). The results revealed the $\mathrm{K}_{\mathrm{IC}}$ of the nanoclay reinforced EP was lower than pristine epoxy, although the fracture surface was much rougher than that of the pristine EP (Figure 6e,f) [83]. Similar to silica, the challenge of adding nanoclay to polymer matrix is dispersion. Hu found that the incorporation of a block copolymer polyethyleneoxide-co-polypropylene oxide-co-polyethylene oxide (PEO-PPO-PEO) into nanoclay modified EP could improve the dispersion of clay in the matrix and prevent clay agglomerations [46]. Moreover, the tensile strength and Young's modulus at $77 \mathrm{~K}$ of this nanoclay modified hybrid nanocomposite were enhanced by $31.0 \%$ and $14.6 \%$, respectively.

The deformation of layered nanoclay under stress could form microvoids and inhibit crack propagation, which does favor to the improvement of the toughness of nanoclay modified polymer-based composites. Besides, the tearing effect by the flake shape of nanoclay is also a fact that increased the toughness of nanoclay modified polymer matrix composites. The transverse cracks in CF reinforced nanoclay-EP composites under cryogenic cycling were significantly reduced when nanoparticle fillers were incorporated at $5 \mathrm{wt} \%$, which was much lower than those used for traditional fillers [84].

\subsection{Enhancing the Cryogenic Performance of Thermoset Polymer by Introducing the Soft Organic Modifiers}

Soft modifiers, such as thermoplastic polymers, rubber, hyperbranched polymer and siloxane also play an important role in improving the toughness of polymer matrix composites $[27,28,85]$. When adding such soft modifiers into the brittle networks of the thermoset matrix, the flexible chains or groups of soft modifiers contribute to the intermolecular force and stress relaxation at the crack tip in the matrix [18,86], resulting in the improvement in the fracture toughness of thermoset polymer. At cryogenic temperature, the resin contracts, and the introduction of soft modifiers increase the occupied volume of the resin chain. Thus, the toughness would be enhanced [87]. 

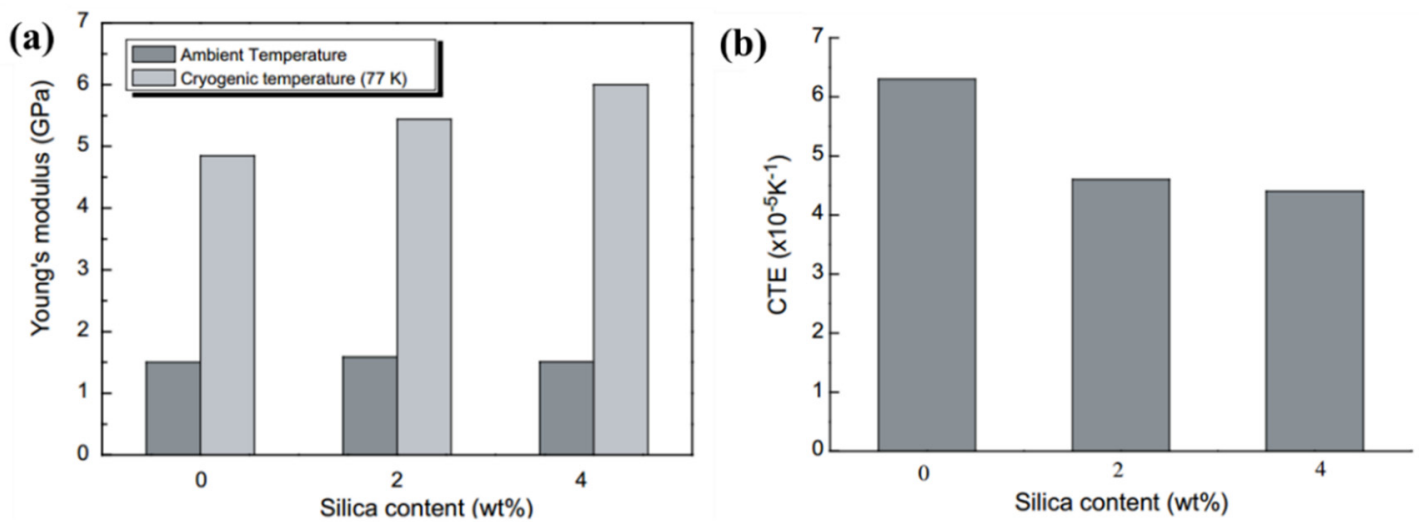

(c)

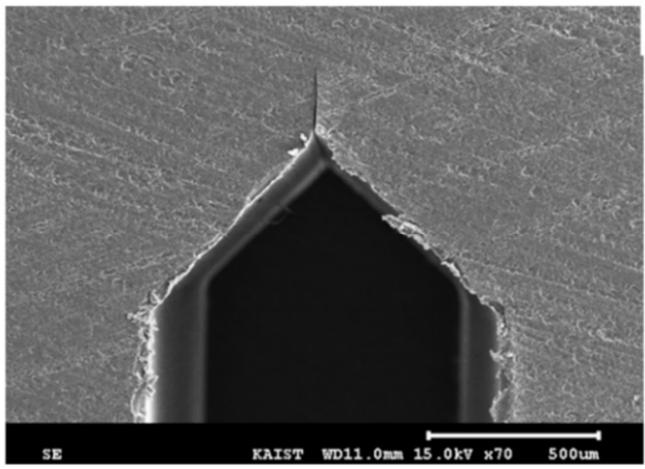

(e)

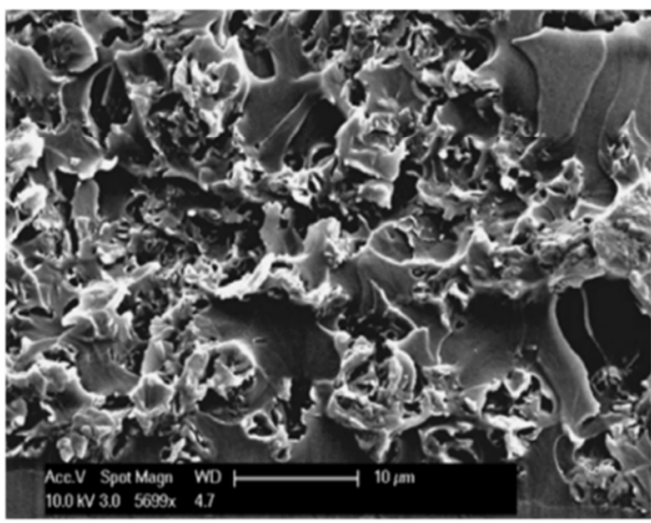

(d)

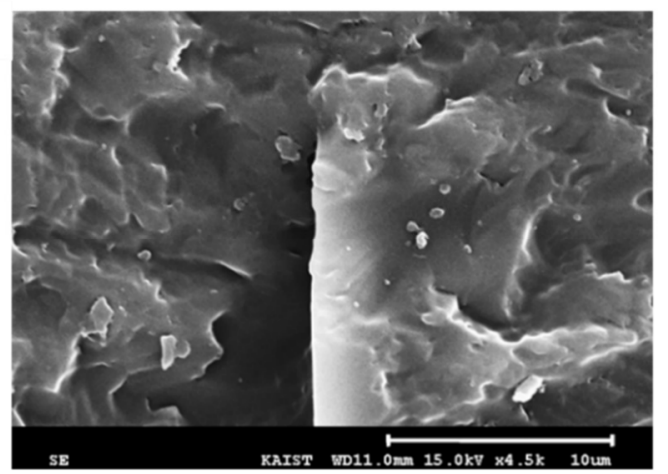

(f)

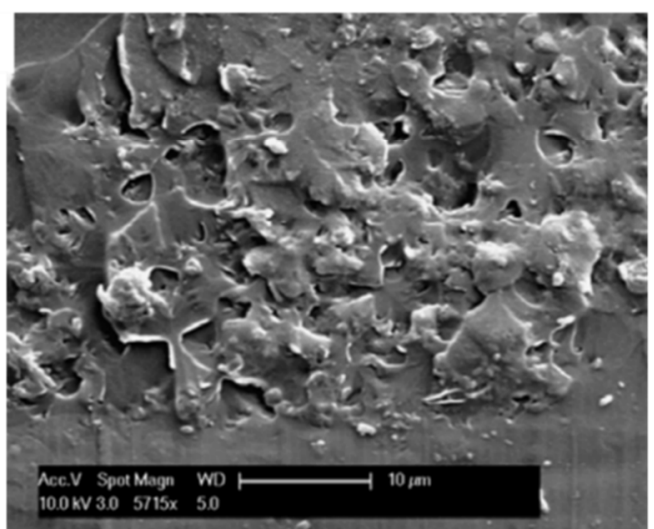

Figure 6. (a)The effect of silica content on Young's modulus of modified polymer composites and (b) the average CTE of modified polymer composites from 298 K to 77 K. Reused with permission from Ref. [45]. Copyright 2018 Elsevier. (c) the single edge notch bend specimen with a very sharp pre-crack, (d) magnified crack tip, fracture surfaces of the specimens tested nanoclay reinforced epoxy at (e) 273 Kand (f) 123 K. Reused with permission from Ref. [83]. Copyright 2008 Elsevier.

\subsubsection{Thermoplastic Polymer}

Toughening the thermoset matrix with thermoplastic polymers, especially engineering thermoplastics, has received much attention because it generally does not cause dramatic decrease to other mechanical or physical properties [88-91].

Owing to the high thermal stability and easy processability, polyethersulfone (PES), was used as an additive into DGEBF type epoxy to enhance the cryogenic mechanical properties by Yang et al. [48]. They found that the tensile strength, tensile fracture strain, and impact strength at $77 \mathrm{~K}$ increased with the PES content increasing up to $20 \mathrm{phr}$. When the content of PES was $20 \mathrm{phr}$, the remarkable improvement of the mechanical properties might be ascribed to the co-continuous phase structure of PES and EP with excellent interfacial adhesion, which was beneficial to absorb the crack energy and able to shear yielding against the crack. While further increasing the ratio of PES content to $25 \mathrm{phr}$ in the 
blend, the disconnected EP particles would be surrounded by the continuous phase of PES, which was phase inversion structure. Thus, the reduction of tensile strength, elongation at break, and impact strength occurred. The cryogenic performance of EP can also be improved by using other thermoplastic resins. During the research conduct by $\mathrm{He}$ et al., three different types of thermoplastics, polyetherimide (PEI), polycarbonate (PC), and polybutylene terephthalate (PBT) were used to modify EP for cryogenic applications [49]. The impact strength of the modified EP at cryogenic temperature increased with increasing thermoplastic content up to $1.5 \mathrm{wt} \%$ and then decreased for further loading $(2.0 \mathrm{wt} \%)$. As shown in Figure 7, unlike PBT and PEI, the fracture surface of PC modified EP at $77 \mathrm{~K}$ reveals a smooth surface with elongated material. It seems that the PC has good bonding with epoxy [92]. The addition of thermoplastic could lower the thermal stress presented in the fiber-EP laminate and improve the micro-crack resistance of fiber-reinforced modified EP composites. They also found that the toughing efficiency of PEI and PC were better than PBT on EP. Wu et al. evaluated the cryogenic temperature $(77 \mathrm{~K})$ mechanical properties of DEGBA type EP composites modified by two Kinds of hydroxyl-terminated polyurethanes (HTPU) with different molecular weights [50]. By changing the HTPU content into the epoxy, two-phase structures of homogeneous phase and sea-island structures were successfully obtained. The homogeneous phase resulted in higher enhancing effects on impact and tensile properties, while the sea-island structure showed better retention in the mixture's glass transition temperature. Li synthesized the EP-functionalized polysiloxane (EPSE) and blended it into bisphenol-F epoxy resin to improve the cryogenic mechanical properties of EP [51]. The EPSE has better compatibility with EP resin because of the existence of an epoxy group in EPSE. The O-Si-O group in the EPSE could enhance the movability of epoxy networks and has better plastic deformation deflecting the crack propagation. Thus, the tensile strength, failure strain, fracture toughness and impact strength at $90 \mathrm{~K}$ increased by $11.2 \%, 33.8 \%, 30.7 \%$ and $14.8 \%$ respectively, when mixed $10 \mathrm{wt} \%$ PSE into DGEBF type EP. Briefly, the toughening of thermoplastic is caused by the resistance to crack propagation and dissipation of energy.
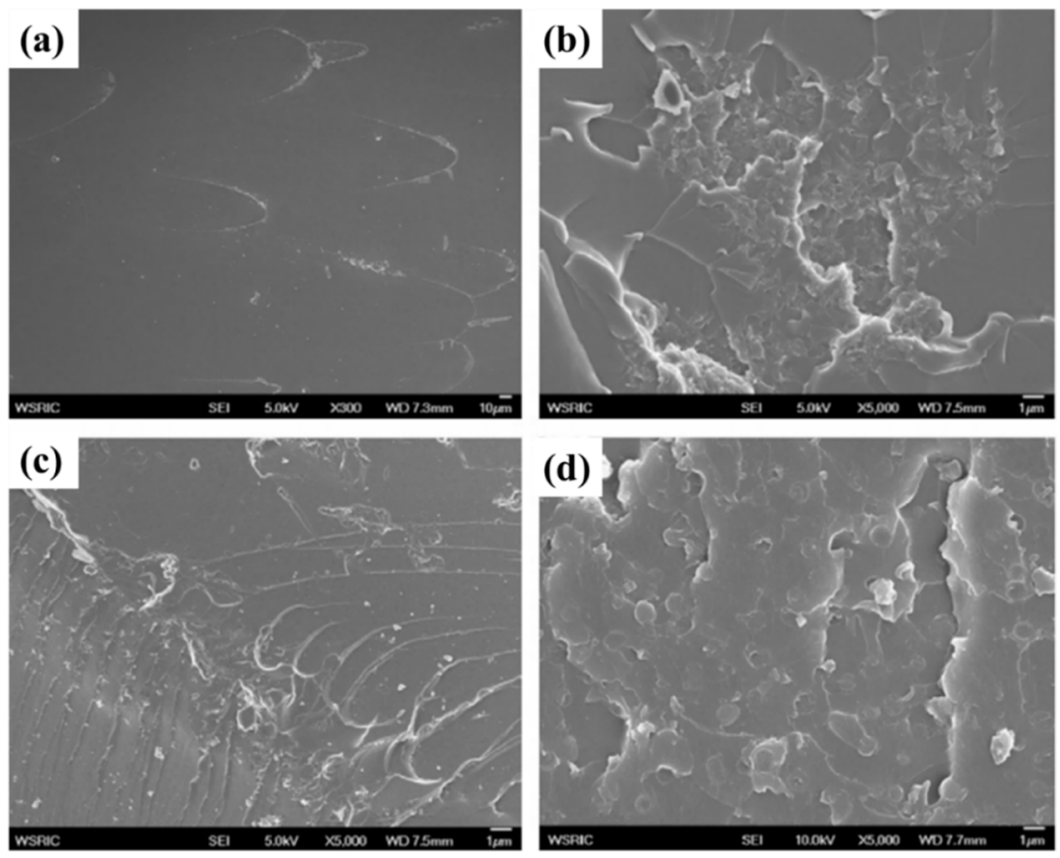

Figure 7. The SEM images of fractured surfaces under impact test at $77 \mathrm{~K}$ of (a) neat epoxy, (b) PBT modified epoxy, (c) PC modified epoxy and (d) PEI modified epoxy. Reused with permission from Ref. [49]. Copyright 2013 Elsevier. 


\subsubsection{Rubber}

Rubber modification as a major toughening approach to overcome the inherent brittleness and high notch sensitivity limit of thermoset polymers has been adopted by many researchers [93-96]. While the addition of rubber also resulted in reductions of both the glass transition temperatures and the interlaminar shear strength of the fiber-reinforced composites [28,97,98].

Preformed rubber particles, core-shell rubber (DP5031, Zeon Chemicals Inc., Shanghai, China), and solid carboxyl functional rubber (Nipol1472, Zeon Chemicals Inc.) were used to modify the resin by Nobelen [99]. Their study focused on the influence of the toughener types on the microcracking response to cryogenic cycling of the fiber-reinforced laminates. Compared to the CF/EP composites toughened with preformed rubber particles or core-shell rubber, the carboxyl-functionalized rubber could present homogeneously in the continuous epoxy phase resulting in a dramatic reduction in the crack density of the laminate when exposed to cryogenic cycling. However, when the DP 5045 and DP 5031 rubber particles were combined to modify the resin matrix, a significant drop in the microcrack density was observed. It can be concluded that the concentration of rubber additive is a more critical factor than the type. They also discussed the influence of carboxyl-terminated butadiene acrylonitrile (CTBN) liquid rubbers on the microcracking response of polymer-based composite materials to cryogenic cycling [100]. In their work, it was also shown that an increase of rubber concentration in CF/EP laminates led to a decrease in the microcrack density which resulting from cryogenic cycling. Similarly, the tensile strength, failure strain and fracture toughness $\left(\mathrm{K}_{\mathrm{IC}}\right)$ at $77 \mathrm{~K}$ of the EP composites were simultaneously enhanced by the addition of Carboxylic nitrile-butadiene nano-rubber (NR) particles [52]. Such mechanical properties at $77 \mathrm{~K}$ were observed to increase with the increase of the NR content up to $15 \mathrm{phr}$. Compared with pure EP, at $77 \mathrm{~K}$, the tensile strength, fracture toughness and failure strain of NR EP blend with $15 \mathrm{phr}$ NR was increased by $40.2 \%, 48.3 \%$ and $55.9 \%$, respectively. The observed increase in mechanical performance could be attributed to the shear yielding deformation of the dissipation zone among the homogeneously dispersed soft NR in the EP matrix brings about the reduction of stress concentration near the crack tip as shown in Figure 8. Nevertheless, Young's modulus of EP resins was slightly decreased with the increase of the NR particles.

(a)

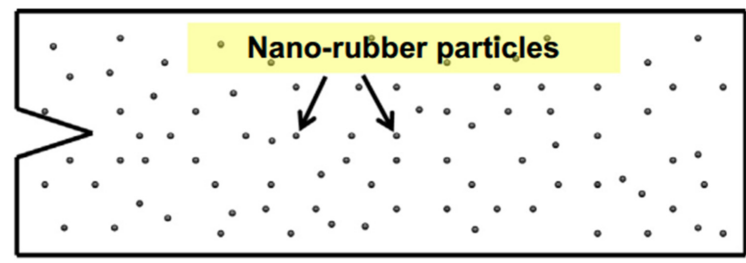

(b)

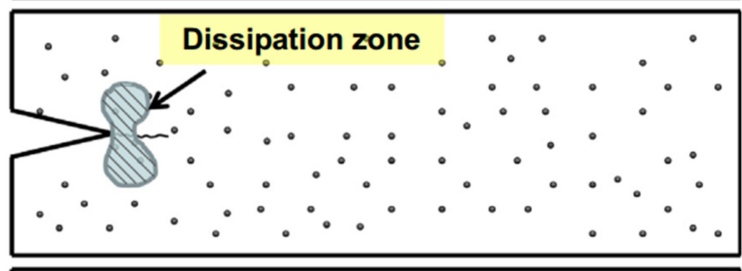

(c)

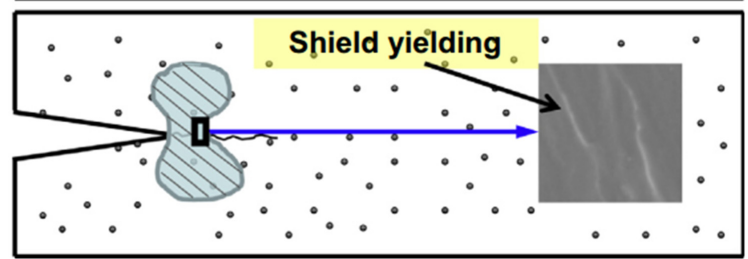

Figure 8. Schematic diagram of the stages of crack propagation in NR particles modified epoxy resins: (a) the notched sample, (b) the crack extends, (c) the crack propagates future. Reused with permission from Ref. [52]. Copyright 2013 Elsevier. 


\subsection{Enhancing the Cryogenic Performance of Thermoset Polymer by Decreasing the Crosslink Density}

It is known that the different network structures cause different properties even if the polymers have the same chemical structure. Due to the chemical reaction, the crosslinking network of thermoset polymer resins is usually rigid and brittle. Thus, controlling the network structures of thermoset polymer is also an effective way to obtain the desired properties [101-104]. Many studies have concluded that the toughness of thermoset EP resin could be enhanced by an alteration of the network topology without using other toughening agents.

Nishijima introduced free volume and free space, which was defined as the unoccupied space between and within the molecules, to explain the toughening mechanism of $\mathrm{EP}$ at a cryogenic temperature [105]. The free space of resin networks can be changed by adding plasticizer, altering the molecular weights, the length of chains, or both. From the fracture toughness test results at LHe temperature $(2 \mathrm{~K})$, the EP with different crosslinking densities was preferable for cryogenic use [106]. Besides, they used DGEBA as a modifier to improve the fracture toughness of the multifunctional EP tetraglycidyl meta-xylenediamine (TGMXDA) resin system at a cryogenic temperature [87]. The results suggested that epoxies with larger molecular weights among crosslink relaxed stress at the crack tip, even at cryogenic temperatures. By comparing the mechanical and thermal properties of EP systems with different chemical structures, network structures and morphology, Ukei found that the two-dimensional network structured epoxies (phenoxy) were promising because they showed high fracture toughness at cryogenic temperatures [107].

Except for changing the structure of epoxies, the crosslinking network structure of the resin system also can be controlled by changing the types and dosages of curing agents, adding compounds with active groups or changing the curing process. Wang studied the cryogenic performance of the phosphorus-containing bisphenol an epoxy resins/aromatic amine systems. The crosslink density of resin systems was controlled by changing the $\mathrm{EP} /$ amine equivalent ratio (SR) [108]. According to this research, the tensile strength, strain energy and impact toughness of the phosphorus-containing bisphenol A EP resin/aromatic amine system reached the maximum when the SR was 0.8. It is known that the internal stress within the bulk material can significantly affect the performance of the finished product by creating micro-cracks and voids. Conversely, the introduction of soft segments into brittle EP resin can dramatically reduce internal stress. Yang et al. introduced flexible diamines (D-230 and D-400) and hyperbranched polymer(H30) into the diethyl toluene diamine (DETD) and Methyltetrahydrophthalic anhydride (MeTHPA) cured DGEBA resin systems respectively and investigated the mechanical properties of the modified EP resin systems at $77 \mathrm{~K}[54,109]$. The results show that the tensile strength and impact strength at $77 \mathrm{~K}$ are simultaneously improved by adding flexible diamines and hyperbranched polymer at an appropriate content. Similarly, the addition of other compounds with the active groups, such as n-butyl glycidyl ether [110], polyethylene glycol [111] and EPfunctionalized polysiloxane [112], could improve the cryogenic performance of DGEBF or DGEBA based EP. Generally, by decreasing the crosslink density or introducing a soft segment to the brittle network of thermoset polymers, the tensile strength and toughness of the polymer would decrease and increase respectively. Meanwhile, at cryogenic temperature, the internal stress could be reduced. These results suggest that the mechanical properties of thermoset polymers at cryogenic temperature could be enhanced by balancing the internal stress and strength reduction.

\section{The Research Development of Thermoplastic Polymer for Cryogenic Application}

The development of thermoplastic resins, especially high-performance engineerings plastics, such as polyamide (PA), polyetheretherketone (PEEK), polyethersulfone (PES), and perfluoroalkoxy (PFA), promises several advantages over thermoset resins in terms of their improved range of mechanical properties and processing techniques available $[34,113,114]$. The thermoplastic resins exhibit several times increases in fracture toughness over epoxies, 
which show great potential for cryogenic applications. There is almost no storage problem with thermoplastic as they can be stored indefinitely at room temperature without deleterious effects $[115,116]$. In general, thermoplastic polymer-based products are often fabricated using conventional molding methods, such as injection-molding, rotational-molding, extrusion, and compression molding. However, it is not suitable for manufacturing large composites structures for the limitation of processing technologies. With the development of prepreg technology and novel processing techniques such as automated tape laying (ATL) [34,117-120], it is possible to make large thermoplastic composites structures and composites tanks [5,7]. Although thermoplastics have attracted researchers' attention for their excellent mechanical properties, lack of a curing stage, less hazardous chemical compositions and improved recycling convenience, the reports about the cryogenic performance of thermoplastics and their composites are rare. Hence, in this section, the research and application development on the cryogenic performance of neat thermoplastic and modified thermoplastic polymeric are discussed, respectively. Despite there are many challenges for cryogenic application, we think the research on the cryogenic performance of thermoplastic polymer and its composites will become a meaningful work in the future.

\subsection{The Cryogenic Performance of Pristine Thermoplastic Polymer}

Among all kinds of thermoplastic polymers, the high-performance engineering thermoplastic polymers are widely applied in various extreme environments for their excellent strength, fracture toughness, weatherability and processability. To date, the reports about the cryogenic performance of thermoplastic and their composites are mainly focused on the high-performance thermoplastic polymer.

In 1990, Ahlborn et al. studied the mechanical performance of CF reinforced PPEK and $\mathrm{PC}$ composites at cryogenic temperature (5 K and $77 \mathrm{~K}$ ) [121]. The result demonstrated that the tensile strength and interlaminar shear strength of $\mathrm{CF} / \mathrm{PEEK}$ composites are better than those of CF/PC composites. Although the interlaminar shear strength of the CF/PC composites was lower, it still performed better than conventional EP-based composites. Besides, the author concluded that the high cryogenic fracture strain of some advanced thermoplastics was beneficial for the tensile fracture strength of fiber-reinforced polymer composites. PEEK has been demonstrated to have superior mechanical properties, wear resistance, chemical resistance, and flame-retardant property, which has attracted some deep researches on the cryogenic performance of PEEK-based composites [122]. In 2001, NASA supported a project that involved the fabrication of a PEEK composite cryogenic fuel line for use on future reusable launch vehicles [123]. Fabrication of the fuel line was done with ADC Acquisition Company's proprietary in-situ thermoplastic fiber placement equipment. Flanagan et al. investigated the permeability of four different CF/PEEK composites manufactured using autoclave after cryogenic cycling [124]. The results show that the permeability of CF/PEEK composites $\left(2.3 \sim 5.2 \times 10^{-17} \mathrm{~mol} / \mathrm{smPa}\right)$ manufactured by the autoclave process was low enough to make it a suitable material choice for cryogenic storage. The schematic of the test setup used for the permeability of composites is shown in Figure 9a. For all samples, cryogenic cycling had little effect on the leak rate of CF/PEEK composites unless cycling caused micro-cracks of the matrix. After cryogenic cycling treatment, the quasi-isotropic laminates $\left(\left[0_{4} / 45_{4} / 135_{4} / 90_{4}\right]_{s}\right)$ suffered extensive micro-cracks and short delaminations (Figure $9 \mathrm{~b})$ and the cross-ply laminates $\left(\left[0_{4} / 90_{4}\right]_{2 s}\right)$ displayed a number of extensive inter-ply delaminations [125]. Grogan et al. [126] studied the damage formation and mechanical properties of automated tape-laid CF/PEEK composites under cryogenic temperature. The damage (void and inclusion content) of tape-laid CF/PEEK laminates were measured using 3D X-ray computed tomography (CT). Compared with the autoclave process, the tape-laid material exhibited lower strength values, particularly in the matrix-dominated directions, which is similar to the reference [124]. Based on the test results and a novel numerical methodology (extended finite element method), they developed a sub-model based on extended finite element method-cohesive zone methodology (XFEM-CZM) to predict intra- and inter-ply damage in an internally pressurized 
cryogenic tank. The results demonstrated that the average crack densities of the plies on the inner surface were higher than their corresponding plies on the outer surface of the tank. Besides, the thermal and mechanical performance of fiber-reinforced thermoplastic polyimide composites at cryogenic temperature was studied by Karen et al. [127]. Interestingly, compared to aging in an unloaded condition, the strength and stiffness of fiber reinforced thermoplastic polyimide composites will increase regardless of laminate lay-up, when aging the material under a constant strain condition at cryogenic temperature. $\mathrm{Li}$ et al. examined the tensile and flexural properties of PES at $77 \mathrm{~K}$ to discuss the application prospect of PES in the cryogenic engineering field [128,129]. The findings suggested that the reinforced structure, prepared methods and load condition can make a significant difference in the cryogenic performance of thermoplastic polymer composites.

(a)

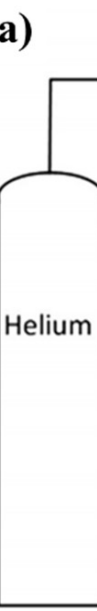

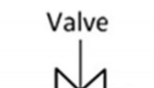

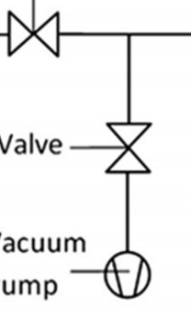

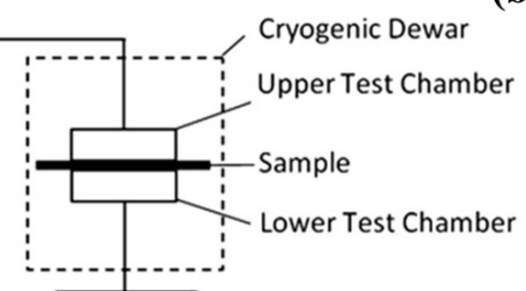
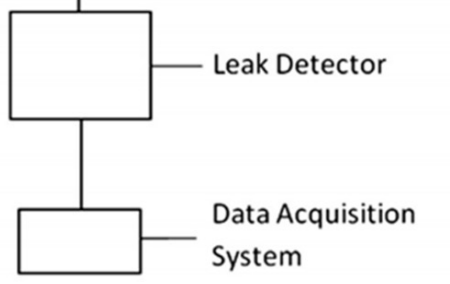

(b)

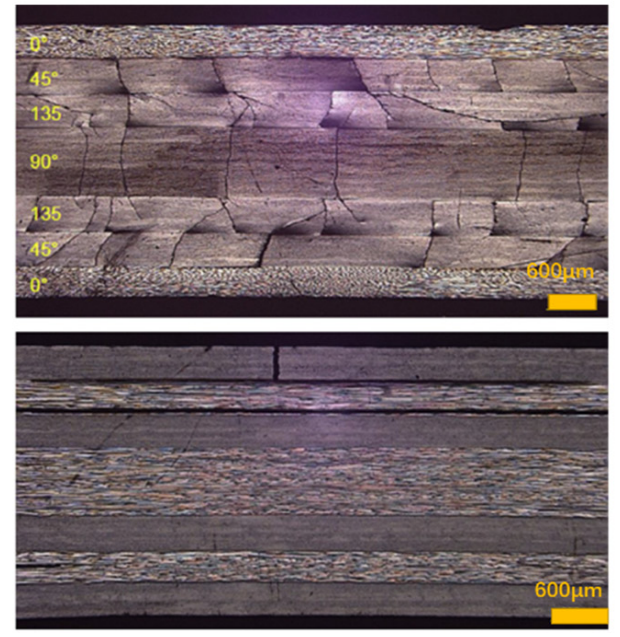

Figure 9. (a) Schematic of the test setup used for permeability testing of composites. Reused with permission from Ref. [125]. Copyright 2017 Elsevier. (b) Cryogenically induced high density microcracking and delaminations in quasi-isotropic laminate (top) and large-scale delamination and single microcrack in cross-ply laminate (bottom). Reused with permission from Ref. [126]. Copyright 2014 Elsevier.

The fatigue performance of polymers can make differences in their service life when they exposed to cryogenic and load environment for a long time. Hartwig et al. [130] discussed the fatigue lives of PEEK and PC under different stress ratio $R$ at $77 \mathrm{~K}$. The results demonstrate that the fatigue lives of PEEK and PC decreased when increasing the stress ration. As shown in the formula 1, under a given stress amplitude $\left(S_{a}\right)$, the mean stress $\left(S_{m}\right)$ increases with the stress ratio.

$$
S_{m}=S_{a}(1+R) /(1-R)
$$

The rise in mean stress indicates that the tensile part of cyclic loading increase, which would promote the crack initiation and propagation and then decrease the fatigues lives. However, they also found that the fatigue endurance limits of PEEK-based composites were lower than EP-based composites. Takeda et al. [131] investigated the stress intensity factors for several crack configurations in glass/epoxy composites with under tension at cryogenic temperatures. The mechanical mean stress combined with the thermal load magnifies the stress intensity factor. The correlation between stress intensity factor and fatigue crack growth is a powerful tool for fail-safe design approaches applied to lightweight structures [132]. In general, the higher stress intensity factor, the greater the possibility to fracture $[133,134]$.

In addition to mechanical properties, manufacturing costs should be taken into account. The application of high-performance thermoplastic polymers is very costly for its high price and relatively complicated manufacturing process. Relatively cheaper thermoplastic materials could be an alternative solution if their performance at cryogenic tempera- 
tures is found to be satisfactory. Weiss investigated the thermal conductivity, expansion and mechanical strength under cryogen temperature (77 K and $4 \mathrm{~K}$ ) of acrylonitrile-butadienestyrene copolymer (ABS) specimens that were processed by 3D printing technology [135]. Compared with EP and high-performance thermoplastic polymer, the cryogenic mechanical properties of ABS are lower. This research provides some important data to evaluate their application prospects in the cryogenic temperature regime. Veltin investigated the performance of fully recyclable, lightweight, low-cost, thermoplastic polypropylene (PP) composite tapes at low temperatures and discussed the applicability of these materials for Liquefied Natural Gas (LNG) applications [136]. At cryogenic temperature, the microcracks between the resin and the fibers due to the CTE difference is a topic of concern. The author introduced the PP-based Single Polymer Composites (SPCs) which contain matrix and reinforcement of the same chemical composition to minimize that issue since the constituent components of the laminates possess the same CTE. The PP-based composites have a skin-core-skin structure where the skin is a PP copolymer and the core is a PP homopolymer. The tensile strength $(77 \mathrm{~K})$ of the [0/90] and [ \pm 45$]$ laminates is $268 \mathrm{MPa}$ and $37 \mathrm{MPa}$, respectively, and the corresponding failure strains are $3.9 \%$ and $6.5 \%$. Furthermore, during the cryogenic low-velocity impact tests on all-PP tubes, the indentation as large as $64 \%$ of the inner diameter generated during the low velocity test at $4.88 \mathrm{~m} / \mathrm{s}$ is fully recovered which demonstrated the viscoelastic nature of the PP at such low temperature. Although the tensile and bending strength of PP-based composites at cryogenic temperature is lower than CF/EP or CF/PEEK composites, it is hopeful to design a structure operating at cryogenic conditions that have for its sufficient ductility and lower cost.

\subsection{The Cryogenic Performance of Modified Thermoplastic Polymer}

Different from thermoset polymers, the main method to improve the mechanical, thermal or electrical properties of thermoplastic is the physical modification method. The introduction of nanomaterial into the polymer is an effective way to enhance its thermal and mechanical properties. Some efforts have been made to improve the cryogenic performance of thermoplastic polymer and its composites by adding a low loading level of nanofillers, such as CNTs, GO and short carbon fibers (SCFs) [128,129,137-140]. Takeda et al. studied the cryogenic tensile response of CNT-reinforced polycarbonate composites and used the finite element simulations method to predict the elastic modulus and the stress state within the composites $[137,138]$. The Young's modulus and $0.2 \%$ offset yield strength at $77 \mathrm{~K}$ increased with increasing CNTs-contents. However, with the CNTs contents increased, at $77 \mathrm{~K}$, the ultimate tensile strength and fracture strain of CNTs-reinforced polycarbonate composites increased and then decreased. And the tensile strength (152 $\mathrm{MPa})$ and fracture stain $(5.18 \%)$ reached the maximum at $1.7 \mathrm{vol} \% \mathrm{CNTs}$. However, compared with the neat polycarbonate, the enhanced effectiveness in cryogenic mechanical property is limited. Wei et al. [139] and Takeda et al. [138] also investigated the flexural and tensile fatigue response of CNTs reinforce polycarbonate composites. As these research demonstrated the $2.5 \mathrm{wt} \% \mathrm{CNTs} /$ polycarbonate composite at $77 \mathrm{~K}$ and room temperature had a longer fatigue life than the $5.0 \mathrm{wt} \% \mathrm{CNTs} /$ polycarbonate composite under the same applied load. The addition of CNTs could improve the fatigue resistance and fatigue lives of polycarbonate at $77 \mathrm{~K}$. The local existence of CNTs agglomerates in $5.0 \mathrm{wt} \%$ $\mathrm{CNTs} /$ polycarbonate composite led to the poor mechanical properties. Therefore, the fatigue properties of the $5.0 \mathrm{wt} \% \mathrm{CNTs} /$ polycarbonate composite is lower than $2.5 \mathrm{wt} \%$ CNTs/polycarbonate composite. Meanwhile, they also found an interesting phenomenon that although the maximum applied load at $77 \mathrm{~K}$ is two times higher than that at room temperature, the fatigue lives of the composites at $77 \mathrm{~K}$ are similar to those at room temperature (Figure 10). Bahçeli et al. [140] studied the cryogenic properties of CNTs reinforced Ultra-high molecular weight polyethylene (UHMWPE) Laminated Composites. The CNTs were added to UHMWPE by two different methods, one is by placing CNTs in the form of buckypaper (CNT BP) during manufacturing, and the other is by producing CNTs 
reinforced high density PE films (CNT/HDPE) through the melt mixing process. Place all of these CNTs based films were into UHMWPE piles and then fabricate different CNTs based film enhanced UHMWPE composites via the hot-pressing technology. Although both types of films could enhance the interlaminar shear strength of UHMWPE composites at room temperature, only the CNTs/HDPE modified UHMWPE composites showed $3 \%$ increase at $77 \mathrm{~K}$. The addition of CNT BP into UHMWPE has shown none improvement in interlaminar shear strength at $77 \mathrm{~K}$.
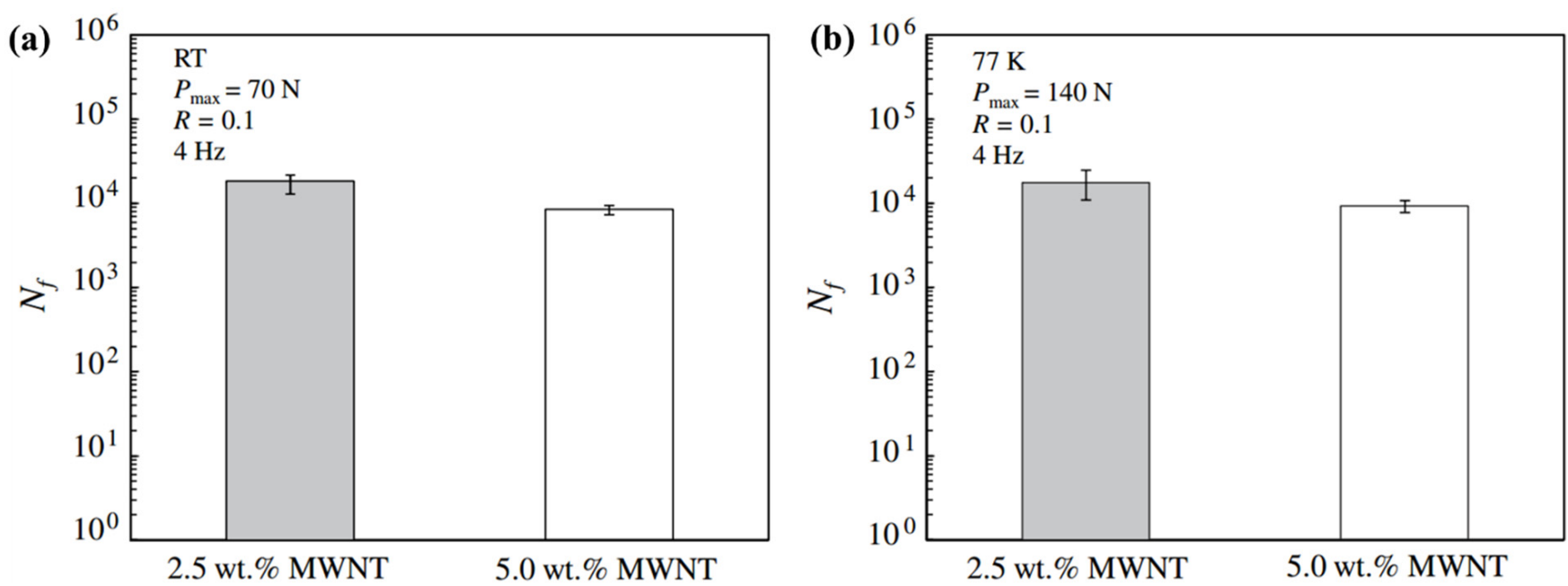

Figure 10. Fatigue lives of CNTS/polycarbonate composites at (a) room temperature and (b) $77 \mathrm{~K}$. Reused with permission from Ref. [139]. Copyright 2014 Elsevier.

LI et al. $[128,129]$ introduced GO, short carbon fibers (SCFs), both GO and SCFs simultaneously, and GO-coated SCFs into PES to get PES-based composites via the extrusion and injection molding techniques. The preparation process of GO-coated SCFs and its based PES composites specimens was shown in Figure 11a. Subsequently, the mechanical properties of PES based composites at $77 \mathrm{~K}$ were examined. They concluded that the GOcoated SCF/PES composites greatly enhanced cryogenic mechanical properties with the highest values compared to other PES composites. At $77 \mathrm{~K}$, the tensile and flexural strength of $0.5 \mathrm{wt} \%$ GO-coated SCF/PES composite reached almost $223 \mathrm{MPa}$ and $415 \mathrm{MPa}$. This phenomenon could be explained by the high interfacial bonding between GO, GO-coated SCF and PES (Figure 11b,c). 
(a)
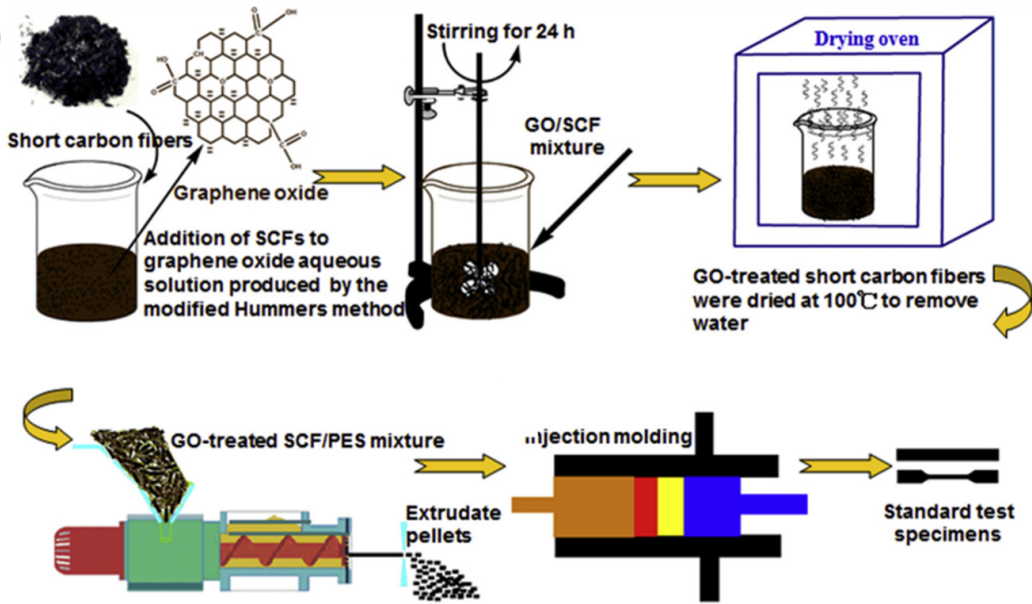

(b)

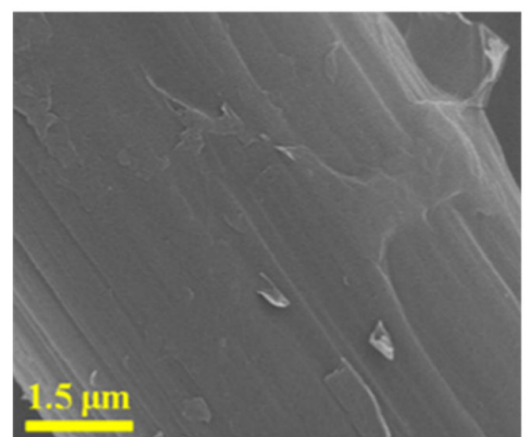

(c)

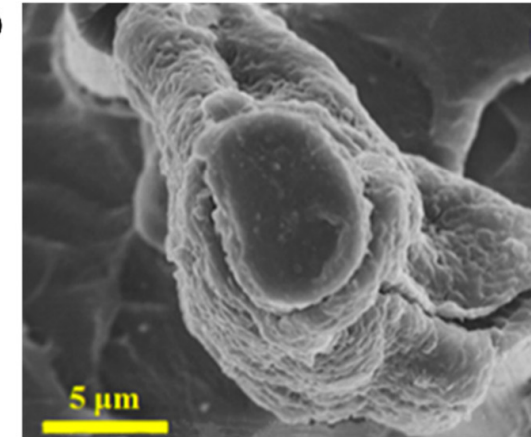

Figure 11. (a) Schematic of GO sizing onto short carbon fibers and the process chart of preparing GO-coated SCFs composite specimens. Reused with permission from Ref. [128]. Copyright 2015 Elsevier. (b) The SEM image of the GO-coated carbon fibers with the $0.5 \mathrm{wt} \% \mathrm{GO}$, (c) The SEM images of the tensile failure surfaces of $0.5 \mathrm{wt} \%$ GO-coated SCF/PES composite at $77 \mathrm{~K}$. Reused with permission from Ref. [129]. Copyright 2016 Elsevier.

\section{The Research Development of the Polymer for Liquid Oxygen Application}

\subsection{The Acceptance-Testing Method of Materials Used in the Liquid Oxygen Environment}

To the polymeric composites applied for LOX, except to meet the mechanical requirements, the composites used in LOX must also be chemically compatible with LOX. [5-7] Compatibility with LOX is a relative quality determined by how readily and to what degree a material will react with oxygen [141]. The chemical mechanism of the LOX compatibility of polymers has been confirmed to be oxidation reactions. It is common Knowledge that many materials burn or explode in the presence of oxygen when exposed to external stimuli such as mechanical impact, crash, friction, or static electricity [142]. Materials that are impact-sensitive with liquid oxygen are generally also sensitive to the reaction by other forms of energy in the presence of oxygen. Meanwhile, the mechanical impact test is easy to conduct and the impact energy can also be controlled. So the impact test is adopted widely by researchers to characterize the compatibility of the material with LOX [17,143]. Since the 1950s, this test method has resulted in a large amount of data. The test equipment, parameters and steps were standardized (ASTM D2512, ASTM G86) [9,17,142]. According to ASTM test standard, the specimen of the material is placed at the bottom of an aluminum cup filled with LOX, a flat-tipped steel pin resting on the specimen, and then a $10 \mathrm{Kg}$ plummet drop from $1 \mathrm{~m}$ height to strike the steel pin(Figure 12a) [142,144-147]. During the test, any explosion, burning, noticeable ash, or charring of specimen is considered as a reaction. As shown in Figure 12b, if there are no reactions in 20 separate specimens, the specimen could be used at the LOX environment. If only one reaction occurs in 20 separate specimens, 40 more samples are needed to test. NO reactions happen in these 40 specimens, this material has the ability to be used in the LOX environment. One or more reactions occur, the material cannot be used in the LOX environment. It has been concluded that it is 
a strict "pass/fail" test that material must meet if they are to be used in the LOX system. Based on the test standard (ASTM D2512-95), Gerzeski proposed a cascade of probabilistic mechanisms that teams Hertzian fracture and Kinetic friction to study the mechanical impact in LOX ignition threshold sensitivity testing of polymer and polymer composites [144]. A portion of the mechanical impact energy is transformed into thermal energy and a local hot spot formed in the specimen. The local temperature of the specimen could be increased by hundreds of degrees Celsius in a short time (1 $1 \mu$ s or less) due to the thermal energy that transformed from mechanical impact energy $[145,146]$. During the mechanical impact test, the contract surface condition between specimen and striker and the relative position of specimen and striker may both affect the test result (Figure 12c,d) [144]. Wang et al. used a commercial finite element analysis tool to analyze the transient fracture mode and energy conversion process of thermoset polymer during the impact test (ASTM D2512) qualitatively [47]. The results demonstrated that about $25 \%$ of the Kinetic energy (98J) was transformed into sliding energy and the rest was transformed into internal energy.

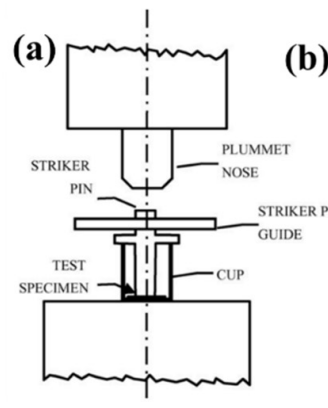

(b)

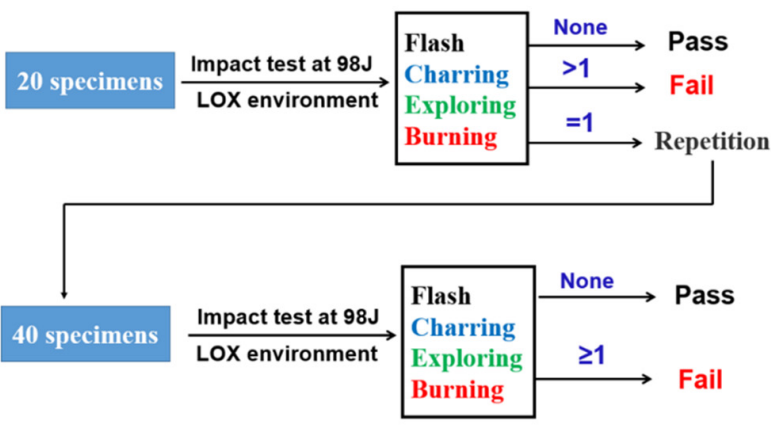

(c)

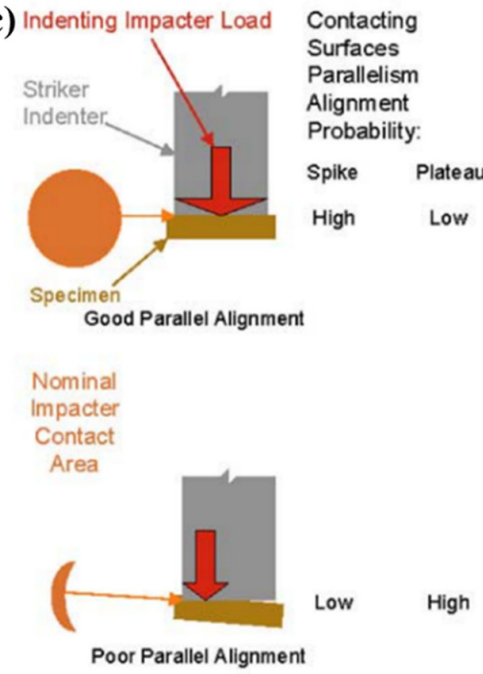

(d)

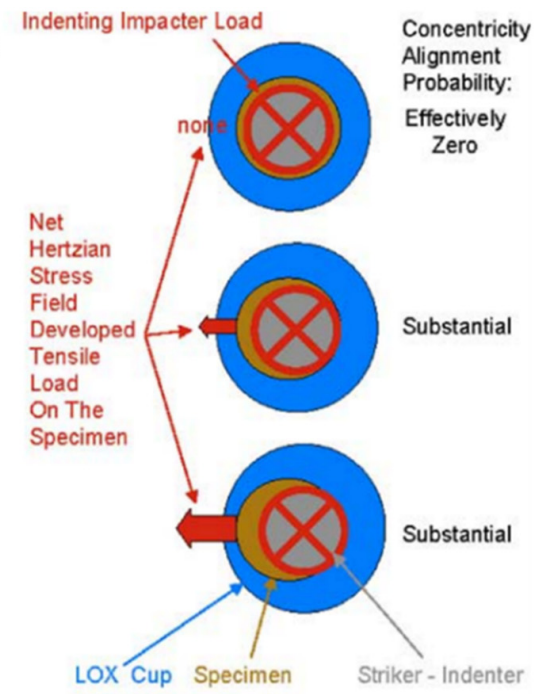

Figure 12. (a) the plummet pin assembly detail of impact test. Reused with permission from Ref. [147]. Copyright 2006 Elsevier. (b) the acceptance criteria of testing material for use in the liquid oxygen system. (c) the contact conditions of the specimen with different surfaces, (d) the possible relative positions of cup, specimen and striker during the mechanical impact test. Reused with permission from Ref. [144]. Copyright 2006 American Society of Testing Materials.

\subsection{Research Progress in Liquid Oxygen Compatibility of Polymers}

In the beginning, researchers mainly focused on the LOX impact sensitivity of some commercial organic material. In 1959, Clippinger and Morris [148] reported the detailed impact Sensitivity test results of some common organic materials on exposure to LOX conducted by the Martin Company's Baltimore Division for the first time. According to the report, except for the Teflon, almost all organic materials were impacted sensitively, such as synthetic elastomers, cellulose silicone, silicate-based oils, nylons, thermo-setting 
phenolics and epoxies. Hoggatt studied the Liquid oxygen impact sensitivity of Mylar, Kapton and Fluorinated ethylene propylene (FEP) coated Kapton polymeric film samples. They confirmed that plain Kapton and FEP films were LOX compatible [149]. In 1967, Clark et al. reviewed the compatibility of structural materials (metals and nonmetals) with oxygen [141]. According to their report, nickel and copper alloys, stainless steels, aluminum alloys, polytetrafluoroethylene (TFE) and polychlorotrifluoroethylene (CTFE) are available for LOX use. Robinson et al. tested fiber-reinforced polymer composites compatibility with LOX [142]. The polymers included EP, bismaleimide, polyimide, phenolic, cyanate ester, PEEK, and fluorinated epoxy. While none of these polymer-based composites could meet the standard mechanical impact test (ASTM D2512-95). Wang et al. investigated the LOX compatibility of EP and cyanate ester co-cured compounds, and confirmed that improving the anti-oxidation properties of the polymer could enhance its LOX compatibility [147]. From the above reports, it can be concluded that the better flame retardancy, the fewer reactions of material occurred during the liquid oxygen impact sensitivity test.

It has been confirmed that the higher impact energy would result in a rapid increase of temperature at the local surface of the specimen to form a hot spot. With the rapid increase of temperature, a lot of relatively high activity radicals such as hydroxyl radicals will be released on the surface of the specimen and even cause local thermal degradation of the polymer. The high activity radicals can cause the incessant chain reaction. Thus, the reactions (charring, noticeable ash, explosion, burning) of organic materials under the impact test will appear [150-152]. Wu et al. analyzed the surface element compositions of polyphenylene sulfide specimens before and after impact tests at LOX environment [150]. They found that the oxygen contents of the specimen with reaction (flash) during the mechanical impact were higher than the specimen without flash. Consequently, it may be concluded that increasing the polymer flame retardancy or thermal stability or both will improve the LOX compatibility of the polymer [147-149]. Therefore, improving the polymer's flame retardancy or thermal stability or both through physical or chemical modifications seems to be a possible way to meet the LOX environment application requirements.

Table 2 lists some modified polymer systems reported in the literature that get through the mechanical impact LOX compatibility test. The detailed information of such material as shown below.

$\mathrm{Wu}$ et al. incorporated 9,10-dihydro-9-oxa-10-phosphaphenanthrene-10-oxide (DOPO) [151] and 10-(2,5-dihydroxyphenyl)-9,10-dihydro-9-oxa-10-phosphaphenanthrene10-oxide (ODOPB) [152] into EP and evaluated its LOX compatibility. The DOPO and ODOPB are two kinds of phosphorus-containing reactive flame retardants with diphenyl structure which has high thermal stability and good oxidation resistance. In this way, the LOX compatibility EP was synthesized successfully. During the impact test, the modified EP would generate phosphoric oxyacid and a lot of phosphoric-oxygenic free radicals. The existence of the acid shields the material with LOX, preventing the oxidation and decomposition of the epoxy resin. The phosphoric-oxygenic free radicals could capture the highly active free radicals such as hydrogen and hydroxyl radicals and then constrain the chain reaction. From the previously published results, the type of EP and cure agent also make an important effect on the LOX compatibility of the modified resin system [153-155]. $\mathrm{Wu}$ et al. reported that the liquid oxygen compatibility of the DOPO modified DGEBA resin system was better than the DOPO modified DGEBF resin system under the same condition [153]. Wu et al. also discussed the LOX compatibility of bromine-modified DGEBA resin curing with different curing agents (DDM and DDS) [154,155]. According to the impact test results, the modified EP resin curing with DDM showed good compatibility with LOX than curing with DDS [155]. Peng et al. introduced a DOPO-based trisiloxane containing phosphorus and silicon compounds into the EP molecular structure to enhance the LOX compatibility of EP resin [156]. By analyzing the surface elements of the specimens before and after mechanical impact in the LOX environment through the XPS method, the Si2p and Si2s signal peaks appeared obviously in the overall XPS spectra (Figure 13a). Meanwhile, based on the XPS test result, the $\mathrm{PO}_{3}$ group in the pyrophos- 
phate and polyphosphate generated during the mechanical impact was also demonstrated (Figure 13b). The existence of Si and P elements breaks the chain reactions caused by oxidation reaction during the mechanical impact at LOX environment, hence improve the LOX compatibility of the polymer. The functioned nanomaterial could improve the flame retardancy, thermal stability and cryogenic mechanical properties of the resin system. Mixing a certain amount of the DOPO modified nanofiller (boehmite) into pure epoxy could also improve the liquid oxygen compatibility of the resin system [157]. Peng et al. synthesized a phosphorous-containing benzoxazine monomer (PBA), and treated PBA as harder to cure EP [158]. They found that the EP/benzoxazine included PBA copolymer could pass the impact test (ASTM D2512-95). Due to the flame-retardant ability of phosphorous and the thermal stability of benzoxazine [159,160], the modified polymer mentioned above showed great potential for manufacturing the LOX composites tank for its comprehensive performance (mechanical properties and LOX compatibility). Therefore, it has been proven that improving the flame retardancy, thermal stability of polymer is an effective way to enhance its LOX compatibility [150-158].

(a)

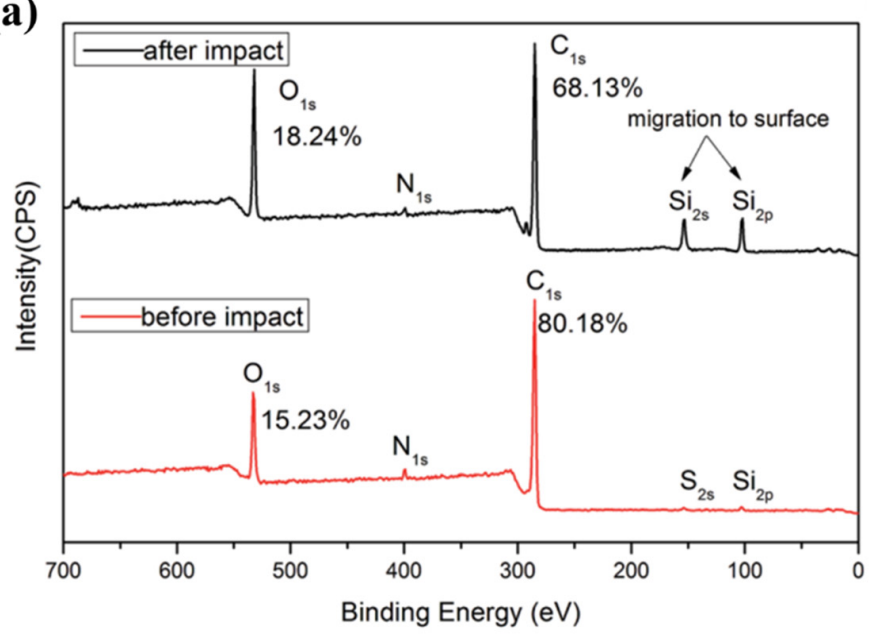

(b)

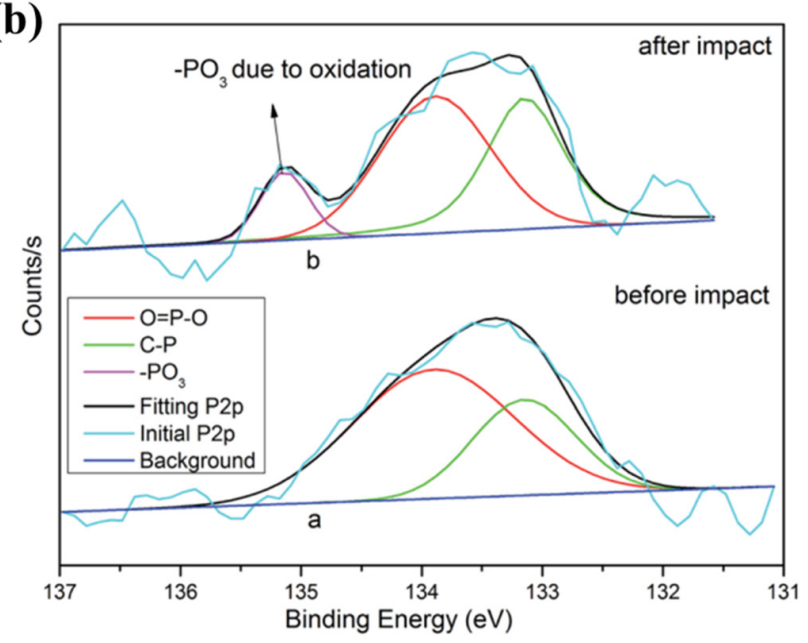

Figure 13. (a) the XPS spectra and (b) P2p peak fitting curves of the specimen before and after mechanical impact under the liquid oxygen environment. Reused with permission from Ref. [159]. Copyright 2016 Royal Society of Chemistry.

Table 2. The cryogenic performance of the reported materials that has the potential ability for liquid oxygen system use.

\begin{tabular}{|c|c|c|c|c|c|}
\hline Resin System $^{1}$ & Modifier $^{1}$ & Contents & Thermal Stability & Mechanical Properties & Ref. \\
\hline DGEBA/DOPO/DDS & DOPO & $7.7 \mathrm{phr}$ & $\mathrm{T}(10 \%): 381^{\circ} \mathrm{C}$ & - & [141] \\
\hline DGEBA/ODOPB/DDM & ODOPB & $18.6 \mathrm{phr}$ & $\begin{array}{l}\mathrm{T}(5 \%): 393{ }^{\circ} \mathrm{C} \\
\mathrm{T}(50 \%): 531{ }^{\circ} \mathrm{C}\end{array}$ & $\begin{array}{l}\text { Tensile strength: } 148.9 \mathrm{MPa} \\
\quad(90 \mathrm{~K}) \\
\text { Tensile fracture strain: } 2.27 \% \\
(90 \mathrm{~K}) \\
\mathrm{K}_{\mathrm{IC}}=1.58 \mathrm{MN} / \mathrm{m}^{3 / 2}(77 \mathrm{~K})\end{array}$ & [152] \\
\hline DGEBA/TBBPA/DDM & TBBPA & $20.5 \mathrm{phr}$ & $\mathrm{T}(5 \%): 365^{\circ} \mathrm{C}$ & $\begin{array}{l}\text { Tensile strength:86.37 MPa } \\
(77 \mathrm{~K}) \\
\mathrm{K}_{\mathrm{IC}}=1.63 \mathrm{MN} / \mathrm{m}^{3 / 2}(77 \mathrm{~K})\end{array}$ & [154] \\
\hline $\begin{array}{c}\text { DGEBA/AlOOH-DOPO-GPTS/ } \\
\text { DDM }\end{array}$ & $\mathrm{AlOOH}-\mathrm{DOPO}-\mathrm{GPTS}$ & $20 \mathrm{wt} \%$ & $\begin{array}{l}\mathrm{T}(5 \%): 367.8^{\circ} \mathrm{C} \\
\mathrm{T}(10 \%): 380.3^{\circ} \mathrm{C}\end{array}$ & $\begin{array}{l}\text { Tensile strength: } 126 \mathrm{MPa} \\
(90 \mathrm{~K}) \\
\text { Tensile fracture strain: } 1.57 \% \\
(90 \mathrm{~K})\end{array}$ & [157] \\
\hline $\mathrm{EP} / \mathrm{PBA} / \mathrm{BA}$ & $\mathrm{PBA} / \mathrm{BA}$ & $\begin{array}{c}24 w t \% / 34.3 \\
w t \%\end{array}$ & $\begin{array}{l}\mathrm{T}(5 \%): 351.2^{\circ} \mathrm{C} \\
\mathrm{T}(50 \%): 533.7^{\circ} \mathrm{C}\end{array}$ & - & [158] \\
\hline
\end{tabular}

${ }^{1}$ Abbreviations:DOPO, 9,10-dihydro-9-oxa-10-phosphaphenanthrene-10-oxide;DDS, 4,4-Diaminobisphenol sulfone; ODOPB, 10-(2,5dihydroxyphenyl)-9,10-dihydro-9-oxa-10-phosphaphenanthrene-10-oxide; TBBPA, Tetrabromobisphenol A; AlOOH, boehmite; GPTS, 3-glycidoxypropyltrimethoxysilane;PBA, phosphorous-containing benzoxazine monomer;BA, bisphenol A benzoxazine. 


\section{Summary and Perspectives}

In this review, we have summarized the research development of polymer for cryogenic application. In general, compared with room temperature, at cryogenic temperature, the strength, modulus and fracture toughness $\left(\mathrm{K}_{\mathrm{IC}}\right)$ of polymers increased. While the impact resistance, tensile fracture strain of polymer decreased dramatically. Accordingly, researchers utilized various methods to enhance the polymer ductility and reduce the thermal stress of polymeric composites. As these reports demonstrated, these modification methods are useful to enhance the cryogenic performance of polymer and polymer-based composites. According to these studies, some functionalized polymers showing great potential for cryogenic application, such as CNTs/EP, GO/EP and phosphoric EP and son on. Meanwhile, for the polymer used in the LOX environment, improving the flame retardancy, thermal stability and toughness of the polymer is an effective way to enhance its LOX compatibility. Despite significant achievements in this field, some directions expect to be explored shortly.

1. Compared with thermosetting or general used thermoplastic polymers, the highperformance engineering thermoplastic polymers have more potential for cryogenic application due to their prominent comprehensive properties (strength, toughness, flame retardancy and recyclable performance). However, the research of highperformance engineering plastic for cryogenic use are seldomly reported. With the development of energy and aerospace, more attention should be paid on the study of high-performance engineering thermoplastic and its composites for cryogenic application.

2. The damage evolution and fracture mechanism and the LOX compatibility mechanism of polymer and its composites at cryogenic temperature need to be studied further. A deep understanding of the cryogenic performance of polymer and its composites would help researchers to find more effective ways to obtain suitable material.

3. During the cryogenic performance test process of the material, several cryogenic media such as $\mathrm{LHe}, \mathrm{LN}_{2}$, and LOX are necessary to provide the cryogenic test environment. Because these cryogenic liquid fluids are extremely volatile, it would take a lot of time and liquids to test the cryogenic performance of the material. Thus, it will be meaningful and interesting to find out the relationship between room temperature performance and cryogenic temperature performance of polymer and its composites or construct the prediction model based on the data of the report to predict the cryogenic performance polymer.

4. The present reports mainly focused on the effectiveness of the methods to improve the cryogenic performance such as mechanical properties, LOX compatibility and impermeability of polymer and its composites. However, the processability of the modified polymer such as viscosity and pot life, which are essential for practical applications, is not included. Future work is required to provide greater insight into the processability of material.

Author Contributions: D.C., J.L., Y.Y., C.G., Y.C., S.L., X.L., H.W., C.P. and Z.W.: conceptualization, writing - original draft preparation, writing-review and editing. All authors have read and agreed to the published version of the manuscript.

Funding: This research was funded by National Key Research and Development Program of China, grant number 2018YFA0702800; National Natural Science Foundation of China, grant numbers 11902063, 11972106, 11772075 and U1837205; Fundamental Research Funds for the Central Universities, grant numbers DUT16ZD214, DUT19ZD101 and DUT19JC32; Shanghai Aerospace Science and Technology Innovation Fund Project, grant number SAST2018-016 and Postdoctoral Science Foundation of China, grant number 2019M661093.

Institutional Review Board Statement: Not applicable.

Informed Consent Statement: Not applicable.

Data Availability Statement: Data sharing not applicable. 
Conflicts of Interest: The authors declare no conflict of interest.

\section{References}

1. Bostock, T.D.; Scurlock, R.G. Introduction. Low-Loss Storage and Handling of Cryogenic Liquids: The Application of Cryogenic Fluid Dynamics; Springer International Publishing: Cham, Switzerland, 2019; pp. 1-11.

2. Zohuri, B. Physics of Cryogenics-An Ultralow Temperature Phenomenon; Elsevier: Amsterdam, The Netherlands, 2018.

3. Yano, O.; Yamaoka, H. Cryogenic properties of polymers. Prog. Polym. Sci. 1995, 20, 585-613. [CrossRef]

4. Irving, S.P.E.; Soutis, C. Polymer Composites in the Aerospace Industry; Woodhead Publishing: Cambridge, UK, 2014.

5. Johnson, T.F.; Sleight, D.W.; Martin, R.A. Structures and Design Phase I Summary for the NASA Composite Cryotank Technology Demonstration Project. In Proceedings of the 54th AIAA/ASME/ASCE/AHS/ASC Structures, Structural Dynamics, and Materials Conference, Boston, MA, USA, 8-11 April 2013. [CrossRef]

6. Sippel, M.; Kopp, A.; Sinkó, K.; Mattsson, D. Advanced Hypersonic Cryo-Tanks Research in CHATT. In Proceedings of the 18th AIAA International Space Planes and Hypersonic Systems and Technologies Conference, Tours, France, 24-28 September 2012. [CrossRef]

7. McCarville, D.A.; Guzman, J.C.; Dillon, A.K.; Jackson, J.R.; Birkland, J.O. 3.5 Design, Manufacture and Test of Cryotank Components; Elsevier: Amsterdam, The Netherlands, 2018; pp. 153-179.

8. Space Exploration Technologies Corp. Capabilities and Services. Available online: https://www.spacex.com/media/ Capabilities\&Services (accessed on 14 October 2020).

9. Achary, D.; Biggs, R.; Bouvier, C.; McBain, M.; Lee, W. Composite Development \& Applications for Cryogenic Tankage. In Proceedings of the 46th AIAA/ASME/ASCE/AHS/ASC Structures, Structural Dynamics \& Materials Conference, Austin, TX, USA, 18-21 April 2005. [CrossRef]

10. Grayson, G.; Cook, L. Performance characteristics of the DC-XA liquid oxygen propellant-acquisition system. In Proceedings of the 32nd Joint Propulsion Conference and Exhibit, Lake Buena vista, FL, USA, 1-3 July 1996. [CrossRef]

11. Glaessgen, E.H.; Reeder, J.R.; Sleight, D.W.; Wang, J.T.; Raju, I.S.; Harris, C.E. Debonding Failure of Sandwich-Composite Cryogenic Fuel Tank with Internal Core Pressure. J. Spacecr. Rocket. 2005, 42, 613-627. [CrossRef]

12. Space. SpaceX Tests Huge Fuel Tank for Mars Colony Spaceship. Available online: https://www.space.com/34759-spacex-marsspaceship-fuel-tank-test.html (accessed on 14 October 2020).

13. Pavlick, M.; Johnson, W.; Jensen, B.; Weiser, E. Evaluation of mechanical properties of advanced polymers for composite cryotank applications. Compos. Part A Appl. Sci. Manuf. 2009, 40, 359-367. [CrossRef]

14. Callaghan, M. Use of resin composites for cryogenic tankage. Cryogenics 1991, 31, 282-287. [CrossRef]

15. Mayes, J.S.; Nickerson, S.; Welsh, J. Multiscale Approach to the Effects of Cryogenic Environments on Polymer Matrix Composites. In Proceedings of the 45th AIAA/ASME/ASCE/AHS/ASC Structures, Structural Dynamics \& Materials Conference, Palm Springs, CA, USA, 19-22 April 2004. [CrossRef]

16. Bechel, V.; Arnold, F. Permeability of polymer composites for cryogenic applications. In Proceedings of the 47th AIAA/ASME/ASCE/AHS/ASC Structures, Structural Dynamics, and Materials Conference, Newport, RI, USA, 1-4 May 2006. [CrossRef]

17. Robinson, M.; Stoltzfus, J.; Owens, T. Composite material compatibility with liquid oxygen. In Proceedings of the 38th Structures, Structural Dynamics, and Materials Conference, Kissimmee, FL, USA, 7-10 April 1997. [CrossRef]

18. Naebe, M.; Abolhasani, M.M.; Khayyam, H.; Amini, A.; Fox, B. Crack Damage in Polymers and Composites: A Review. Polym. Rev. 2016, 56, 31-69. [CrossRef]

19. Sumikawa, M.; Shindo, Y.; Takeda, T.; Narita, F.; Takano, S.; Sanada, K. Analysis of Mode I Interlaminar Fracture and Damage Behavior of GFRP Woven Laminates at Cryogenic Temperatures. J. Compos. Mater. 2005, 39, 2053-2066. [CrossRef]

20. Shindo, Y.; Sato, T.; Narita, F.; Sanada, K. Mode II Interlaminar Fracture and Damage Evaluation of GFRP Woven Laminates at Cryogenic Temperatures using the 4ENF Specimen. J. Compos. Mater. 2008, 42, 1089-1101. [CrossRef]

21. Miura, M.; Shindo, Y.; Narita, F.; Watanabe, S.; Suzuki, M. Mode III fatigue delamination growth of glass fiber reinforced polymer woven laminates at cryogenic temperatures. Cryogenics 2009, 49, 407-412. [CrossRef]

22. Shindo, Y.; Takahashi, S.; Takeda, T.; Narita, F.; Watanabe, S. Mixed-mode interlaminar fracture and damage characterization in woven fabric-reinforced glass/epoxy composite laminates at cryogenic temperatures using the finite element and improved test methods. Eng. Fract. Mech. 2008, 75, 5101-5112. [CrossRef]

23. Choi, S.; Sankar, B.V. Micromechanical Analysis of Composite Laminates at Cryogenic Temperatures. J. Compos. Mater. 2005, 40, 1077-1091. [CrossRef]

24. Yang, L.; Li, Z.; Xu, H.; Wu, Z. Prediction on residual stresses of carbon/epoxy composite at cryogenic temperature. Polym. Compos. 2019, 40, 3412-3420. [CrossRef]

25. Takeda, T.; Shindo, Y.; Narita, F. Three-dimensional thermoelastic analysis of cracked plain weave glass/epoxy composites at cryogenic temperatures. Compos. Sci. Technol. 2004, 64, 2353-2362. [CrossRef]

26. Domun, N.; Hadavinia, H.; Zhang, T.; Sainsbury, T.; Liaghat, G.H.; Vahid, S. Improving the fracture toughness and the strength of epoxy using nanomaterials-A review of the current status. Nanoscale 2015, 7, 10294-10329. [CrossRef] [PubMed]

27. Chruściel, J.J.; Leśniak, E. Modification of epoxy resins with functional silanes, polysiloxanes, silsesquioxanes, silica and silicates. Prog. Polym. Sci. 2015, 41, 67-121. [CrossRef] 
28. Bagheri, R.; Marouf, B.T.; Pearson, R.A. Rubber-Toughened Epoxies: A Critical Review. Polym. Rev. 2009, 49, 201-225. [CrossRef]

29. Vidil, T.; Tournilhac, F.; Musso, S.; Robisson, A.; Leibler, L. Control of reactions and network structures of epoxy thermosets. Prog. Polym. Sci. 2016, 62, 126-179. [CrossRef]

30. Marouf, B.T.; Mai, Y.-W.; Bagheri, R.; Pearson, R.A. Toughening of Epoxy Nanocomposites: Nano and Hybrid Effects. Polym. Rev. 2016, 56, 70-112. [CrossRef]

31. Fallahi, H.; Taheri-Behrooz, F.; Asadi, A. Nonlinear Mechanical Response of Polymer Matrix Composites: A Review. Polym. Rev. 2019, 60, 42-85. [CrossRef]

32. Jesson, D.A.; Watts, J.F. The Interface and Interphase in Polymer Matrix Composites: Effect on Mechanical Properties and Methods for Identification. Polym. Rev. 2012, 52, 321-354. [CrossRef]

33. Biron, M.; Marichal, O. Thermoplastics and Thermoplastic Composites; William Andrew: Waltham, MA, USA, 2013.

34. Yao, S.-S.; Jin, F.-L.; Rhee, K.Y.; Hui, D.; Park, S.J. Recent advances in carbon-fiber-reinforced thermoplastic composites: A review. Compos. Part B Eng. 2018, 142, 241-250. [CrossRef]

35. Dodiuk, H.; Goodman, S.H. Handbook of Thermoset Plastics; William Andrew: Waltham, MA, USA, 2014.

36. Capricho, J.C.; Fox, B.L.; Hameed, N. Multifunctionality in Epoxy Resins. Polym. Rev. 2019, 60, 1-41. [CrossRef]

37. Chen, Z.-K.; Yang, J.-P.; Ni, Q.-Q.; Fu, S.-Y.; Huang, Y.-G. Reinforcement of epoxy resins with multi-walled carbon nanotubes for enhancing cryogenic mechanical properties. Polymer 2009, 50, 4753-4759. [CrossRef]

38. Jia, L.; Qi, P.; Shi, K.; Liu, X.; Ma, W.; Lin, S.; Zhang, F.; Jia, X.; Cai, Q.; Yang, X. High performance epoxy-based composites for cryogenic use: A approach based on synergetic strengthening effects of epoxy grafted polyurethane and MWCNTs-NH2. Compos. Sci. Technol. 2019, 184, 107865. [CrossRef]

39. Yi, X.F.; Mishra, A.K.; Kim, N.H.; Ku, B.-C.; Lee, J.H. Synergistic effects of oxidized CNTs and reactive oligomer on the fracture toughness and mechanical properties of epoxy. Compos. Part A Appl. Sci. Manuf. 2013, 49, 58-67. [CrossRef]

40. Shen, X.-J.; Liu, Y.; Xiao, H.-M.; Feng, Q.-P.; Yu, Z.-Z.; Fu, S.-Y. The reinforcing effect of graphene nanosheets on the cryogenic mechanical properties of epoxy resins. Compos. Sci. Technol. 2012, 72, 1581-1587. [CrossRef]

41. Hussein, A.; Sarkar, S.; Lee, K.; Kim, B. Cryogenic fracture behavior of epoxy reinforced by a novel graphene oxide/poly(pphenylenediamine) hybrid. Compos. Part B Eng. 2017, 129, 133-142. [CrossRef]

42. Lee, J.K.; Song, S.; Kim, B. Functionalized graphene sheets-epoxy based nanocomposite for cryotank composite application. Polym. Compos. 2012, 33, 1263-1273. [CrossRef]

43. Prusty, R.K.; Rathore, D.K.; Sahoo, S.; Parida, V.; Ray, B.C. Mechanical behaviour of graphene oxide embedded epoxy nanocomposite at sub- and above- zero temperature environments. Compos. Commun. 2017, 3, 47-50. [CrossRef]

44. He, Y.; Chen, Q.; Yang, S.; Lu, C.; Feng, M.; Jiang, Y.; Cao, G.; Zhang, J.; Liu, C. Micro-crack behavior of carbon fiber reinforced $\mathrm{Fe}_{3} \mathrm{O}_{4}$ /graphene oxide modified epoxy composites for cryogenic application. Compos. Part A Appl. Sci. Manuf. $2018,108,12-22$. [CrossRef]

45. Huang, C.; Fu, S.; Zhang, Y.; Lauke, B.; Li, L.; Ye, L. Cryogenic properties of $\mathrm{SiO}_{2}$ /epoxy nanocomposites. Cryogenics 2005, 45, 450-454. [CrossRef]

46. Hu, C.; Sun, Y.; Yu, J.; Huo, J. Simultaneously enhanced cryogenic mechanical behaviors of cyanate ester/epoxy resins by poly(ethylene oxide)-co -poly(propylene oxide)-co -poly(ethylene oxide) (PEO-PPO-PEO) block copolymer and clay. Polym. Compos. 2017, 38, 2237-2247. [CrossRef]

47. Wang, H.; Sun, T.; Peng, C.; Wu, Z. Effect of different silane coupling agents on cryogenic properties of silica-reinforced epoxy composites. High Perform. Polym. 2018, 30, 24-37. [CrossRef]

48. Yang, G.; Zheng, B.; Yang, J.-P.; Xu, G.-S.; Fu, S. Preparation and cryogenic mechanical properties of epoxy resins modified by poly(ethersulfone). J. Polym. Sci. Part A Polym. Chem. 2007, 46, 612-624. [CrossRef]

49. He, Y.-X.; Li, Q.; Kuila, T.; Kim, N.H.; Jiang, T.; Lau, K.-T.; Lee, J.H. Micro-crack behavior of carbon fiber reinforced thermoplastic modified epoxy composites for cryogenic applications. Compos. Part B Eng. 2013, 44, 533-539. [CrossRef]

50. Wu, T.; Liu, Y.; Li, N.; Huang, G.-W.; Qu, C.-B.; Xiao, H.-M. Cryogenic mechanical properties of epoxy resin toughened by hydroxyl-terminated polyurethane. Polym. Test. 2019, 74, 45-56. [CrossRef]

51. Li, S.; Chen, D.; Yuan, Y.; Gao, C.; Cui, Y.; Wang, H.; Liu, X.; Liu, M.; Wu, Z. Influence of flexible molecular structure on the cryogenic mechanical properties of epoxy matrix and carbon fiber/epoxy composite laminate. Mater. Des. 2020, 195, 109028. [CrossRef]

52. Zhao, Y.; Chen, Z.-K.; Liu, Y.; Xiao, H.-M.; Feng, Q.; Fu, S.-Y. Simultaneously enhanced cryogenic tensile strength and fracture toughness of epoxy resins by carboxylic nitrile-butadiene nano-rubber. Compos. Part A Appl. Sci. Manuf. 2013, 55, 178-187. [CrossRef]

53. Chen, Q.; Gao, B.; Chen, J. Properties of impregnation resin added to multifunctional epoxy at cryogenic temperature. J. Appl. Polym. Sci. 2003, 89, 1385-1389. [CrossRef]

54. Yang, J.-P.; Chen, Z.-K.; Yang, G.; Fu, S.; Ye, L. Simultaneous improvements in the cryogenic tensile strength, ductility and impact strength of epoxy resins by a hyperbranched polymer. Polymer 2008, 49, 3168-3175. [CrossRef]

55. Byrne, M.T.; Gun'Ko, Y.K. Recent Advances in Research on Carbon Nanotube-Polymer Composites. Adv. Mater. 2010, 22, 1672-1688. [CrossRef]

56. Rahmat, M.; Hubert, P. Carbon nanotube-polymer interactions in nanocomposites: A review. Compos. Sci. Technol. 2011, 72, 72-84. [CrossRef] 
57. Chen, J.; Yan, L.; Song, W.; Xu, D. Interfacial characteristics of carbon nanotube-polymer composites: A review. Compos. Part A Appl. Sci. Manuf. 2018, 114, 149-169. [CrossRef]

58. Liu, S.; Chevali, V.S.; Xu, Z.; Hui, D.; Wang, H. A review of extending performance of epoxy resins using carbon nanomaterials. Compos. Part B Eng. 2018, 136, 197-214. [CrossRef]

59. Papageorgiou, D.G.; Li, Z.; Liu, M.; Kinloch, I.A.; Young, R.J. Mechanisms of mechanical reinforcement by graphene and carbon nanotubes in polymer nanocomposites. Nanoscale 2020, 12, 2228-2267. [CrossRef]

60. Kim, M.-G.; Moon, J.-B.; Kim, C.-G. Effect of CNT functionalization on crack resistance of a carbon/epoxy composite at a cryogenic temperature. Compos. Part A Appl. Sci. Manuf. 2012, 43, 1620-1627. [CrossRef]

61. Prusty, R.K.; Rathore, D.K.; Ray, B.C. Evaluation of the role of functionalized CNT in glass fiber/epoxy composite at above- and sub-zero temperatures: Emphasizing interfacial microstructures. Compos. Part A Appl. Sci. Manuf. 2017, 101, 215-226. [CrossRef]

62. Takeda, T.; Fan, W.; Feng, Q.-P.; Fu, S.-Y.; Narita, F.; Shindo, Y. Cryogenic mechanical properties of woven glass/epoxy composites modified with multi-walled carbon nanotube and n-butyl glycidyl ether under tensile static and cyclic loadings. Cryogenics 2013, 58, 33-37. [CrossRef]

63. Liu, Y.; Yang, J.-P.; Xiao, H.-M.; Qu, C.-B.; Feng, Q.; Fu, S.; Shindo, Y. Role of matrix modification on interlaminar shear strength of glass fibre/epoxy composites. Compos. Part B Eng. 2012, 43, 95-98. [CrossRef]

64. Novoselov, K.S.; Geim, A.K.; Morozov, S.V.; Jiang, D.; Zhang, Y.; Dubonos, S.V.; Grigorieva, I.V.; Firsov, A.A. Electric Field Effect in Atomically Thin Carbon Films. Science 2004, 306, 666-669. [CrossRef]

65. Long, M.; Wang, P.; Fang, H.; Hu, W. Progress, Challenges, and Opportunities for 2D Material Based Photodetectors. Adv. Funct. Mater. 2019, 29, 1803807. [CrossRef]

66. Wang, X.; Jin, J.; Song, M. An investigation of the mechanism of graphene toughening epoxy. Carbon 2013, 65, 324-333. [CrossRef]

67. Mohan, V.B.; Lau, K.-T.; Hui, D.; Bhattacharyya, D. Graphene-based materials and their composites: A review on production, applications and product limitations. Compos. Part B Eng. 2018, 142, 200-220. [CrossRef]

68. Kuilla, T.; Bhadra, S.; Yao, D.; Kim, N.H.; Bose, S.; Lee, J.H. Recent advances in graphene based polymer composites. Prog. Polym. Sci. 2010, 35, 1350-1375. [CrossRef]

69. Bhattacharya, M. Polymer Nanocomposites-A Comparison between Carbon Nanotubes, Graphene, and Clay as Nanofillers. Materials 2016, 9, 262. [CrossRef] [PubMed]

70. Hu, K.; Kulkarni, D.D.; Choi, I.; Tsukruk, V.V. Graphene-polymer nanocomposites for structural and functional applications. Prog. Polym. Sci. 2014, 39, 1934-1972. [CrossRef]

71. Su, Q.; Pang, S.; Alijani, V.; Li, C.; Feng, X.; Müllen, K. Composites of Graphene with Large Aromatic Molecules. Adv. Mater. 2009, 21, 3191-3195. [CrossRef]

72. Mittal, G.; Dhand, V.; Rhee, K.Y.; Park, S.J.; Lee, W.R. A review on carbon nanotubes and graphene as fillers in reinforced polymer nanocomposites. J. Ind. Eng. Chem. 2015, 21, 11-25. [CrossRef]

73. Francis, R.; Joy, N.; Aparna, E.P.; Vijayan, R. Polymer Grafted Inorganic Nanoparticles, Preparation, Properties, and Applications: A Review. Polym. Rev. 2014, 54, 268-347. [CrossRef]

74. Zabihi, O.; Ahmadi, M.; Nikafshar, S.; Preyeswary, K.C.; Naebe, M. A technical review on epoxy-clay nanocomposites: Structure, properties, and their applications in fiber reinforced composites. Compos. Part B Eng. 2018, 135, 1-24. [CrossRef]

75. Kaya, G.G.; Deveci, H. Synergistic effects of silica aerogels/xerogels on properties of polymer composites: A review. J. Ind. Eng. Chem. 2020, 89, 13-27. [CrossRef]

76. Luo, H.; Ding, J.; Huang, Z.; Yang, T. Investigation of properties of nano-silica modified epoxy resin films and composites using RFI technology. Compos. Part B Eng. 2018, 155, 288-298. [CrossRef]

77. Azimi, R.; Roghani-Mamaqani, H.; Gholipour-Mahmoudalilou, M. Grafting poly (amidoamine) dendrimer-modified silica nanoparticles to graphene oxide for preparation of a composite and curing agent for epoxy resin. Polymer 2017, 126, 152-161. [CrossRef]

78. Withers, G.; Yu, Y.; Khabashesku, V.; Cercone, L.; Hadjiev, V.G.; Souza, J.; Davis, D. Improved mechanical properties of an epoxy glass-fiber composite reinforced with surface organomodified nanoclays. Compos. Part B Eng. 2015, 72, 175-182. [CrossRef]

79. Tatar, A.C.; Kaybal, H.B.; Ulus, H.; Demir, O.; Avc1, A. Erbakan University Evaluation of low-velocity impact behavior of epoxy nanocomposite laminates modified with $\mathrm{SiO}_{2}$ nanoparticles at cryogenic temperatures. Res. Eng. Struct. Mater. 2019, 5, 115-125. [CrossRef]

80. Scatteia, L.; Lenzi, F.; Totaro, G.; Cantoni, S.; Franceschi, M. Composite and Nanocomposite Materials Evaluation and Assessment for Cryogenic Propellant Storage. In Proceedings of the AIAA/CIRA 13th International Space Planes and Hypersonics Systems and Technologies Conference, Capua, Italy, 16-20 May 2005. [CrossRef]

81. Miller, S.G.; Meador, M.A. Polymer- Layered silicate nanocomposites for cryotank Applications. In Proceedings of the 48th AIAA/ASME/ASCE/AHS/ASC Structures, Structural Dynamics, and Materials Conference, Honolulu, HI, USA, 23-26 April 2007. [CrossRef]

82. Ma, H.-L.; Zhang, X.; Lau, K.-T.; Shi, S.-Q. Effect of nanoclay concentration on the lap joint shear performance of nanoclay/epoxy adhesive at cryogenic condition. J. Compos. Mater. 2018, 52, 2477-2482. [CrossRef]

83. Kim, B.C.; Park, S.W.; Gil Lee, D. Fracture toughness of the nano-particle reinforced epoxy composite. Compos. Struct. 2008, 86, 69-77. [CrossRef] 
84. Timmerman, J.F.; Hayes, B.S.; Seferis, J.C. Nanoclay reinforcement effects on the cryogenic microcracking of carbon fiber/epoxy composites. Compos. Sci. Technol. 2002, 62, 1249-1258. [CrossRef]

85. Farooq, U.; Teuwen, J.; Dransfeld, C. Toughening of Epoxy Systems with Interpenetrating Polymer Network (IPN): A Review. Polymer 2020, 12, 1908. [CrossRef]

86. Deng, S.; Djukic, L.; Paton, R.; Ye, L. Thermoplastic-epoxy interactions and their potential applications in joining composite structures-A review. Compos. Part A Appl. Sci. Manuf. 2015, 68, 121-132. [CrossRef]

87. Nishijima, S.; Honda, Y.; Tagawa, S.; Okada, T. Study of epoxy resin for cryogenic use by positron annihilation method. J. Radioanal. Nucl. Chem. 1996, 211, 93-101. [CrossRef]

88. Cheng, X.; Wu, Q.; Morgan, S.E.; Wiggins, J. Morphologies and mechanical properties of polyethersulfone modified epoxy blends through multifunctional epoxy composition. J. Appl. Polym. Sci. 2017, 134. [CrossRef]

89. Rider, A.N.; Yeo, E.; Gopalakrishna, J.; Thostenson, E.T.; Brack, N. Hierarchical composites with high-volume fractions of carbon nanotubes: Influence of plasma surface treatment and thermoplastic nanophase-modified epoxy. Carbon 2015, 94, 971-981. [CrossRef]

90. Augustine, D.; Vijayalakshmi, K.; Sadhana, R.; Mathew, D.; Nair, C.P.R. Hydroxyl terminated PEEK-toughened epoxy-amino novolac phthalonitrile blends-Synthesis, cure studies and adhesive properties. Polymer 2014, 55, 6006-6016. [CrossRef]

91. Zhang, Y.; Hasegawa, K.; Kamo, S.; Takagi, K.; Takahara, A. Enhanced adhesion effect of epoxy resin on carbon fiber-reinforced Poly(etheretherketone) via surface initiated photopolymerization of glycidyl methacrylate. Polymer 2020, 209, 123036. [CrossRef]

92. Bakar, M.; Kobusińska, J.; Szczerba, J. Mechanical properties of epoxy resin modified with polycarbonate and reactive polybutadiene. J. Appl. Polym. Sci. 2007, 106, 2892-2897. [CrossRef]

93. Tang, L.-C.; Zhang, H.; Sprenger, S.; Ye, L.; Zhang, Z. Fracture mechanisms of epoxy-based ternary composites filled with rigid-soft particles. Compos. Sci. Technol. 2012, 72, 558-565. [CrossRef]

94. Arias, M.L.; Frontini, P.M.; Williams, R.J. Analysis of the damage zone around the crack tip for two rubber-modified epoxy matrices exhibiting different toughenability. Polymer 2003, 44, 1537-1546. [CrossRef]

95. Reddy, K.C.; Bharathiraja, G.; Jayakumar, V. Mode I fracture toughness analysis of rubber particulate epoxy composite. Mater. Today Proc. 2020, 22, 759-761. [CrossRef]

96. Zhang, L.; Chao, M.; Hui, D.; Liu, J.; Zheng, J.; Lei, W.; Zhou, X.; Wang, R.; Zhang, L. Enhanced interfacial interaction and excellent performance of silica/epoxy group-functionalized styrene-butadiene rubber (SBR) nanocomposites without any coupling agent. Compos. Part B Eng. 2017, 114, 356-364. [CrossRef]

97. Yang, B.; Wang, W.; Huang, J. Synergic effects of poly(vinyl butyral) on toughening epoxies by nanostructured rubbers. Polymer 2015, 77, 129-142. [CrossRef]

98. Wang, J.; Zhang, X.; Jiang, L.; Qiao, J. Advances in toughened polymer materials by structured rubber particles. Prog. Polym. Sci. 2019, 98, 101160. [CrossRef]

99. Nobelen, M.; Hayes, B.S.; Seferis, J.C. Influence of elastomer distribution on the cryogenic microcracking of carbon fiber/epoxy composites. J. Appl. Polym. Sci. 2003, 90, 2268-2275. [CrossRef]

100. Nobelen, M.; Hayes, B.S.; Seferis, J.C. Cryogenic microcracking of rubber toughened composites. Polym. Compos. 2010, 24, 723-730. [CrossRef]

101. Bandyopadhyay, A.; Valavala, P.K.; Clancy, T.C.; Wise, K.E.; Odegard, G.M. Molecular modeling of crosslinked epoxy polymers: The effect of crosslink density on thermomechanical properties. Polymer 2011, 52, 2445-2452. [CrossRef]

102. Park, H.; Kim, B.; Choi, J.; Cho, M. Influences of the molecular structures of curing agents on the inelastic-deformation mechanisms in highly-crosslinked epoxy polymers. Polymer 2018, 136, 128-142. [CrossRef]

103. Kim, B.; Choi, J.; Yu, S.; Yang, S.; Cho, M. Influence of crosslink ratio on the thermomechanical properties of polymer nanocomposites and interphase: A molecular dynamics simulation. In Proceedings of the 55th AIAA/ASME/ASCE/AHS/ASC Structures, Structural Dynamics, and Materials Conference, National Harbor, MD, USA, 13-17 January 2014. [CrossRef]

104. Heba, F.; Mouzali, M.; Abadie, M.J.M. Effect of the crosslinking degree on curing kinetics of an epoxy-acid copolymer system. J. Appl. Polym. Sci. 2003, 90, 2834-2839. [CrossRef]

105. Nishijima, S.; Honda, Y.; Okada, T. Application of the positron annihilation method for evaluation of organic materials for cryogenic use. Cryogenics 1995, 35, 779-781. [CrossRef]

106. Sawa, F.; Nishijima, S.; Okada, T. Molecular design of an epoxy for cryogenic temperatures. Cryogenics 1995, 35, 767-769. [CrossRef]

107. Ueki, T.; Nishijima, S.; Izumi, Y. Designing of epoxy resin systems for cryogenic use. Cryogenics 2005, 45, 141-148. [CrossRef]

108. Wang, H.; Li, S.; Yuan, Y.; Liu, X.; Sun, T.; Wu, Z. Study of the epoxy/amine equivalent ratio on thermal properties, cryogenic mechanical properties, and liquid oxygen compatibility of the bisphenol A epoxy resin containing phosphorus. High Perform. Polym. 2020, 32, 429-443. [CrossRef]

109. Yang, G.; Fu, S.-Y.; Yang, J.-P. Preparation and mechanical properties of modified epoxy resins with flexible diamines. Polymer 2007, 48, 302-310. [CrossRef]

110. Chen, Z.-K.; Yang, G.; Yang, J.-P.; Fu, S.; Ye, L.; Huang, Y.-G. Simultaneously increasing cryogenic strength, ductility and impact resistance of epoxy resins modified by n-butyl glycidyl ether. Polymer 2009, 50, 1316-1323. [CrossRef]

111. Feng, Q.; Yang, J.; Liu, Y.; Xiao, H.; Fu, S. Simultaneously Enhanced Cryogenic Tensile Strength, Ductility and Impact Resistance of Epoxy Resins by Polyethylene Glycol. J. Mater. Sci. Technol. 2014, 30, 90-96. [CrossRef] 
112. Li, S.; Chen, D.; Gao, C.; Yuan, Y.; Wang, H.; Liu, X.; Hu, B.; Ma, J.; Liu, M.; Wu, Z. Epoxy-functionalized polysiloxane/Nano-SiO 2 synergistic reinforcement in cryogenic mechanical properties of epoxy and carbon fiber reinforced epoxy laminate. Compos. Sci. Technol. 2020, 198, 108292. [CrossRef]

113. Tsai, L.D.; Hwang, M.R. Thermoplastic and Thermosetting Polymers and Composites; Nova Science Publishers: New York, NY, USA, 2011.

114. Miche, B. Thermoplastics and Thermoplastic Composites; Elsevier Science \& Technology: Oxford, UK, 2013.

115. Boisse, P. Advances in Composites Manufacturing and Process Design; Woodhead Publishing: Cambridge, UK, 2015.

116. Zhang, J.; Chevali, V.S.; Wang, H.; Wang, C.H. Current status of carbon fibre and carbon fibre composites recycling. Compos. Part B Eng. 2020, 193, 108053. [CrossRef]

117. Penumakala, P.K.; Santo, J.; Thomas, A. A critical review on the fused deposition modeling of thermoplastic polymer composites. Compos. Part B Eng. 2020, 201, 108336. [CrossRef]

118. Rajan, S.; Sutton, M.A.; Sockalingam, S.; McMakin, W.; Gurdal, Z.; Kidane, A. Simulations and experiments for automated fiber placement of prepreg slit tape: Wrinkle formation and fundamental observations. Compos. Part B Eng. 2020, $201,108287$. [CrossRef]

119. He, K.; Nie, H.; Yan, C. The Intelligent Composite Panels Manufacturing Technology Based on Tape-laying Automatic System. Procedia CIRP 2016, 56, 610-613. [CrossRef]

120. Dhinakaran, V.; Surendar, K.; Riyaz, M.H.; Ravichandran, M. Review on study of thermosetting and thermoplastic materials in the automated fiber placement process. Mater. Today Proc. 2020, 27, 812-815. [CrossRef]

121. Ahlborn, K. Cryogenic mechanical response of carbon fibre reinforced plastics with thermoplastic matrices to quasi-static loads. Cryogenics 1991, 31, 252-256. [CrossRef]

122. Thiruchitrambalam, M.; Kumar, D.B.; Shanmugam, D.; Jawaid, M. A review on PEEK composites-Manufacturing methods, properties and applications. Mater. Today Proc. 2020, 33, 1085-1092. [CrossRef]

123. Becker, R.; Nettles, A.; Bucinell, R.; Langone, R.; Mondo, J. Fabrication of a peek/graphite composite cryogenic fuel line. In Proceedings of the 6th International SAMPE Symposium and Exhibition, Long Beach, CA, USA, 6-10 May 2001.

124. Flanagan, M.; Grogan, D.; Goggins, J.; Appel, S.; Doyle, K.; Leen, S.B.; Brádaigh, C.M.Ó. Permeability of carbon fibre PEEK composites for cryogenic storage tanks of future space launchers. Compos. Part A Appl. Sci. Manuf. 2017, 101, 173-184. [CrossRef]

125. Grogan, D.; Leen, S.; Semprimoschnig, C.; Brádaigh, C.M.Ó. Damage characterisation of cryogenically cycled carbon fibre/PEEK laminates. Compos. Part A Appl. Sci. Manuf. 2014, 66, 237-250. [CrossRef]

126. Grogan, D.; Brádaigh, C.Ó.; McGarry, J.; Leen, S. Damage and permeability in tape-laid thermoplastic composite cryogenic tanks. Compos. Part. A Appl. Sci. Manuf. 2015, 78, 390-402. [CrossRef]

127. Whitley, K.; Gates, T. Thermal/Mechanical Response and Damage Growth in Polymeric Composites at Cryogenic Temperatures. In Proceedings of the 43rd AIAA/ASME/ASCE/AHS/ASC Structures, Structural Dynamics, and Materials Conference, Denver, CO, USA, 22-25 April 2002. [CrossRef]

128. Li, F.; Liu, Y.; Qu, C.-B.; Xiao, H.-M.; Hua, Y.; Sui, G.-X.; Fu, S.-Y. Enhanced mechanical properties of short carbon fiber reinforced polyethersulfone composites by graphene oxide coating. Polymer 2015, 59, 155-165. [CrossRef]

129. Li, F.; Hua, Y.; Qu, C.-B.; Xiao, H.-M.; Fu, S. Greatly enhanced cryogenic mechanical properties of short carbon fiber/polyethersulfone composites by graphene oxide coating. Compos. Part A Appl. Sci. Manuf. 2016, 89, 47-55. [CrossRef]

130. Hartwig, G.; Hübner, R.; Knaak, S. Fatigue Behavior of Polymers and Composites at Cryogenic Temperatures. Adv. Cryog. Eng. Mater. 1996, 155-159. [CrossRef]

131. Takeda, T.; Shindo, Y.; Narita, F.; Sanada, K. Stress Intensity Factors for Woven Glass/Epoxy Laminates with Cracks at Cryogenic Temperatures. Mech. Adv. Mater. Struct. 2004, 11, 109-132. [CrossRef]

132. Paarmann, M.; Sander, M. Analytical determination of stress intensity factors in thick walled thermally loaded components. Eng. Fract. Mech. 2020, 235, 107125. [CrossRef]

133. Sajith, S.; Murthy, K.; Robi, P. Estimation of stress intensity factors from crack flank displacements. Mater. Today Proc. 2020, 24, 887-894. [CrossRef]

134. Kahn, H.; Chen, L.; Ballarini, R.; Heuer, A. Mechanical fatigue of polysilicon: Effects of mean stress and stress amplitude. ACTA Mater. 2006, 54, 667-678. [CrossRef]

135. Weiss, K.-P.; Bagrets, N.; Lange, C.; Goldacker, W.; Wohlgemuth, J. Thermal and mechanical properties of selected 3D printed thermoplastics in the cryogenic temperature regime. IOP Conf. Ser. Mater. Sci. Eng. 2015, 102, 012022. [CrossRef]

136. Atli-Veltin, B. Cryogenic performance of single polymer polypropylene composites. Cryogenics 2018, 90, 86-95. [CrossRef]

137. Takeda, T.; Narita, F.; Kuronuma, Y.; Shindo, Y. Numerical and experimental study on the response of multi-walled carbon nanotube/polymer composites under compressive loading. Int. J. Mater. Struct. Integr. 2013, 7, 4-21. [CrossRef]

138. Takeda, T.; Shindo, Y.; Wei, Z.; Kuronuma, Y.; Narita, F. Fatigue failure and electrical resistance behaviors of carbon nanotubebased polymer composites under uniaxial tension-tension loading in a cryogenic environment. J. Compos. Mater. 2014, 49, 457-463. [CrossRef]

139. Wei, Z.; Takeda, T.; Narita, F.; Shindo, Y. Flexural fatigue performance and electrical resistance response of carbon nanotube-based polymer composites at cryogenic temperatures. Cryogenics 2014, 59, 44-48. [CrossRef]

140. Bahceli, G. Cryogenic Properties of CNT Reinforced UHMWPE Laminated Composites. In Proceedings of the AIAA SciTech 2019 Forum, San Diego, CA, USA, 7-11 January 2019. [CrossRef] 
141. Clark, A.F.; Hust, J.G. A Review of the Compatibility of Structural Materials with Oxygen. AIAA J. 1974, 12, 441-454. [CrossRef]

142. Kim, R.; Lee, W.; Camping, J.; Bowman, K. Impact Reaction of Composites in Liquid Oxygen. In Proceedings of the 46th AIAA/ASME/ASCE/AHS/ASC Structures, Structural Dynamics \& Materials Conference, Austin, TX, USA, 18-21 April 2005. [CrossRef]

143. Livingstona, R.A.; Schweitzer, J.S.; Parsons, A.M.; Arens, E.E. Feasibility Study for Measurement of Insulation Compaction in the Cryogenic Rocket Fuel Storage Tanks at Kennedy Space Center by Fast/Thermal Neutron Techniques. AIP Conf. Proc. 2014, 1581, 1832-1839. [CrossRef]

144. Dean, S.; Gerzeski, R. Hertzian Fracture, Kinetic Friction and the Mechanical Impact LOX Compatibility Testing of Polymers and Polymer Matrix Composites. J. ASTM Int. 2006, 3, 100549. [CrossRef]

145. Dean, S.W.; Gerzeski, R. Fractography of ASTM D2512 Tested Polymeric Isotropic Material Residuals Generated External to the Impacting Indenter. J. ASTM Int. 2010, 7. [CrossRef]

146. Mitchell, M.R.; Link, R.E.; Gerzeski, R. LOX Compatible Toughened Bismaleimide Matrix Thermally Conductive Fiber Composites Part II: ASTM D2512 Specimen Fabrication, Cleaning and Testing. J. Test. Eval. 2008, 36. [CrossRef]

147. Wang, G.; Li, X.; Yan, R.; Xing, S. The study on compatibility of polymer matrix resins with liquid oxygen. Mater. Sci. Eng. B 2006, 132, 70-73. [CrossRef]

148. Clippinger, D.; Morris, G. Impact Sensitivity of Organic Materials on Exposure to Liquid Oxygen. Aircr. Eng. Aerosp. Technol. 1959, 31, 204-205. [CrossRef]

149. Hoggatt, J.T. Compatibility of Polymeric Films with Liquid Oxygen; NASA CR-72I34; National Aeronautics and Space Administration Office of Scientific and Technical Information: Washington, DC, USA, 1967.

150. Wu, Z.; Gao, F.; Yan, J.; Wang, Z. Damage mechanism of polyphenylene sulfide resin in liquid oxygen. Iran. Polym. J. 2012, 21, 185-190. [CrossRef]

151. Wu, Z.; Li, J.; Chen, Y.; Wang, Z.; Li, S. Effect of 9,10-dihydro-9-oxa-10-phosphaphenanthrene-10-oxide on liquid oxygen compatibility of bisphenol a epoxy resin. J. Appl. Polym. Sci. 2014, 131. [CrossRef]

152. Li, J.; Liu, X.; Wu, Z.; Wang, Z. The effect of 10-(2,5-dihydroxyphenyl)-9, 10-dihydro-9-oxa-10-phosphaphenanthrene- 10-oxide on liquid oxygen compatibility and cryogenic mechanical properties of epoxy resins. High. Perform. Polym. 2016, 28, 820-830. [CrossRef]

153. Wu, Z.; Li, J.; Wang, Z. Liquid oxygen compatibility and thermal stability of bisphenol A and bisphenol F epoxy resins modified by DOPO. Polym. Adv. Technol. 2015, 26, 153-159. [CrossRef]

154. Wu, Z.; Li, S.; Liu, M.; Wang, Z.; Li, J. Synthesis and characterization of a liquid oxygen-compatible epoxy resin. High. Perform. Polym. 2014, 27, 74-84. [CrossRef]

155. Wu, Z.; Li, S.; Liu, M.; Wang, Z.; Liu, X. Liquid oxygen compatible epoxy resin: Modification and characterization. RSC Adv. 2015, 5, 11325-11333. [CrossRef]

156. Peng, C.; Li, J.; Wu, Z.; Peng, W.; Zhou, D. Investigating into the liquid oxygen compatibility of a modified epoxy resin containing silicon/phosphorus and its mechanical behavior at cryogenic temperature. RSC Adv. 2016, 6, 38300-38309. [CrossRef]

157. Wang, H.; Peng, C.; Li, S.; Liu, X.; Wu, Z. Improvement of the liquid oxygen compatibility of epoxy via the addition of surface-modified boehmite. J. Appl. Polym. Sci. 2018, 135. [CrossRef]

158. Peng, C.; Gao, C.; Yuan, Y.; Wu, Z.; Zhou, D. Synthesis and application of a benzoxazine-type phosphorus-containing monomer on epoxy/benzoxazine copolymer: Thermal stability and compatibility with liquid oxygen. Polym. Degrad. Stab. 2018, 157, 131-142. [CrossRef]

159. Lyu, Y.; Ishida, H. Natural-sourced benzoxazine resins, homopolymers, blends and composites: A review of their synthesis, manufacturing and applications. Prog. Polym. Sci. 2019, 99, 101168. [CrossRef]

160. Sini, N.; Bijwe, J.; Varma, I.K. Thermal behaviour of bis-benzoxazines derived from renewable feed stock 'vanillin'. Polym. Degrad. Stab. 2014, 109, 270-277. [CrossRef] 